\title{
SALVAGUARDA \\ DE LOS DERECHOS \\ FUNDAMENTALES FRENTE \\ AL RUIDO
}

\author{
POR \\ GENOVEVA SERRANO-SÚÑER HOYOS* \\ $Y$ \\ PEDRO J. TENORIO SÁNCHEZ**
}

\section{INTRODUCCIÓN}

Diariamente inciden sobre el ambiente numerosos focos de emisiones sonoras que contribuyen a generar situaciones poco recomendables desde el punto de vista sanitario y del bienestar. De hecho, junto a los ruidos tradicionales que siguen afectando a importantes sectores de la economía (actividades comerciales, de transporte, de servicio...), los ciudadanos se han tenido que enfrentar a nuevas actividades que, aun orientadas a su propio bienestar, ofrecen en ocasiones más perjuicios que ventajas. Esto es lo que ocurre, por ejemplo, con los locales y actividades de ocio. En lugares tradicionalmente tranquilos dentro de una aglomeración urbana, este tipo de locales se han ido multiplicando, en muchas ocasiones sin las pertinentes licencias, con unos dueños buenos conocedores de la pasividad de las Administraciones Públicas en esta

* Doctor en Derecho y Profesora Tutora de Derecho Constitucional de la UNED. Autora exclusiva de los siguientes epígrafes: II.1.A; II.1.B; II.1.C; II.2.A; II.2.B; III.1 y 2.

** Letrado del Tribunal Constitucional y Profesor Titular de Derecho Constitucional de la UNED. Autor exclusivo de los restantes epígrafes, esto es: I; II.1.D; II.2.C; IV; V y VI. 
materia. Salvo contadas excepciones, nos encontramos ante un panorama desolador de dejadez, incompetencia y pasividad de los responsables que acaso esté comenzando a cambiar. ${ }^{1}$ En efecto, las autoridades legislativas y administrativas sólo han tomado conciencia de este tipo de contaminación y de las graves consecuencias tanto físicas como psicológicas que pueden derivarse por el sometimiento a un ruido excesivo, en tiempos relativamente recientes. Quizás esta incipiente reacción haya estado motivada por la consideración unánime del ruido ambiental como uno de los mayores problemas medioambientales en Europa.

Ahora bien, si se analiza la respuesta del resto de los poderes públicos, es preciso reconocer la utilidad y eficacia del tratamiento jurisprudencial de este grave y creciente problema. En relación con las numerosas demandas promovidas por particulares con la pretensión de que cesen las distintas actividades sonoras, hay que resaltar la jurisprudencia del Tribunal Europeo de Derechos Humanos de Estrasburgo (en adelante, TEDH) que, en muchas ocasiones ha servido de pauta a la igualmente válida y sugerente jurisprudencia constitucional.

Ambas, en efecto, han desarrollado en los últimos años, como una concreción del derecho constitucional al medio ambiente ${ }^{2}$, la ecologización ("greening» en la expresión inglesa ${ }^{3}$ ) de determinados derechos fundamentales, el descubrimiento de una nueva dimensión ambiental en algunos derechos fundamentales por medio de la interpretación según la cual, en casos de sobresaliente gravedad, ciertos daños ecológicos pueden poner en peligro la salud o la integridad de la persona, atentando contra el derecho a la vida y la integridad física y moral (caso de nuestro Tribunal Constitucional $^{4}$, art. $15 \mathrm{CE}$ ), o bien lesionar el derecho de las personas a la

1 Vid.Martin-Retortillo, L.: "El ruido: una pesadilla del Justicia», en Tercer encuen tro de Estudios sobe el Justicia deZaragoza, mayo 2002, p. 166.

2 Sobre la emergencia de la "Constitución ambiental», vid.Ruiz-Rico Ruiz, G.: EI derecho constitucional al medio ambiente (dimensi n jurisprude西rat lo Blanch, Valencia, 2000, págs. 15-106.

${ }^{3}$ Vid.Lozano Cutanda, B.: "La ecologización de los derechos fundamentales: la doctrina López Ostra c. España, Guerra y otros c. Italia y Hatton y otros c. Reino Unido del TEDH y su recepción por nuestro TC", en Revista Espa ola de Derecho EurGivitas no 1, enero-marzo 2002, págs. 175-205.

${ }^{4}$ En el asunto interestatal Irlanda c. Reino Unido, el TEDH estimó que el hecho de que los detenidos se encontrasen en una sala, en la que no cesaba de resonar un fuerte pitido era una práctica de tratamientos inhumanos y degradantes (art. 3 del Convenio). 
intimidad personal y familiar y a la inviolabilidad del domicilio (caso del Tribunal Constitucional y del TEDH, arts. $18 \mathrm{CE}$ y $8 \mathrm{CEDH})$.

Sin dejar de hacer referencia a las resoluciones más importantes dictadas por el TEDH, así como su relación con la actual doctrina de nuestro Alto Tribunal, en el presente trabajo se tratarán especialmente las dos recientes SSTC 16/2004, de 23 de febrero, y 25/2004, de 26 de febrero. Siguiendo la pauta de la mayoría de los fallos emitidos sobre la materia objeto de estudio, ambas sentencias no han estado exentas de profundas deliberaciones a la vista de los votos particulares que en ellas se integran. De ellas, se destacarán tres cuestiones:

En primer lugar, la incidencia del ruido sobre la integridad real y efectiva de determinados derechos fundamentales. De conformidad con la nueva Ley del Ruido, el mandato constitucional de proteger la salud (art. $43 \mathrm{CE}$ ) y el medio ambiente (art. $45 \mathrm{CE}$ ) engloban en su alcance la protección contra la contaminación acústica. Pero además, esta protección constitucional encuentra su apoyo en algunos derechos fundamentales reconocidos expresamente en nuestra Norma Suprema. Para algunos, según se explicará en su momento, la necesidad de proteger al ciudadano ante este panorama desolador de pasividad y dejadez de la mayoría de los responsables ha contribuido a que la tutela judicial frente al ruido se haya encuadrado en el ámbito de los derechos fundamentales. Para otros, en cambio, la existencia de esta nueva necesidad no es suficiente para justificar la consideración de la misma como "nuevo derecho constitucional no escrito". Para incluir en la Constitución "nuevos» derechos es necesario que la misma ofrezca un fundamento para proteger situaciones o necesidades que no menciona expresamente. ${ }^{5}$

En este sentido, se hará especial referencia a la STC 16/2004 por haber reafirmado de manera clara y contundente los derechos fundamentales implicados en este tipo de agresiones tras una larga evolución jurisprudencial. Antes de exponer sus líneas básicas de argumentación, como muestra del estado actual de la cuestión, se mencionarán las grandes aportaciones de la jurisprudencia constitucional (SSTC 199/1996, 119/2001) y del TEDH (López Ostra, Guerra, Powel y Rayner, Hatton y otros) que han sido decisivas para el giro de la doctrina del Tribunal Constitucional.

5 Como señala Díaz Revorio, F.J.: "Tribunal Constitucional y Derechos Constitucionales "no escritos», en La Justicia Constitucional en el Estado democr tico, Tirant lo Blanch, Valencia, 2000, p. 233. 
En segundo lugar, se analizará la sorprendente divergencia mantenida por las Salas Primera y Segunda de nuestro Alto Tribunal ante una posible vulneración del principio de legalidad cuyo ejercicio real y efectivo está expresamente previsto en la Constitución. En ambos fallos, el problema que se plantea es determinar si la resolución sancionadora municipal impuesta con motivo de las agresiones acústicas se ajusta o no a las exigencias que impone el art. 25.1 CE por tratarse de una materia que, al margen de determinados ámbitos específicos como el laboral, no ha sido tradicionalmente objeto de atención preferente en la legislación protectora del medio ambiente. Aún refiriéndose tan sólo a la protección jurídicopenal, estas situaciones deberían de servir al legislador para replantearse el tema del ruido, pero no de una forma legislativamente mendicante, sino de una manera nítida y taxativa en consonancia con la relevancia que tiene y sin circunloquios peligrosos de recurrir a lo que, en definitiva, es una técnica de elusión al principio de legalidad. ${ }^{6}$

Unido a lo anterior, se comentará en tercer y último lugar la muy eficaz función impulsora del Tribunal Constitucional y del TEDH por regular una materia cuya regulación manifiestamente incompleta ha contribuido a deteriorar de forma alarmante la protección solicitada por todos los que han sufrido las consecuencias de este tipo de agresiones. En este sentido, se aludirá someramente a algunos de los logros obtenidos tanto en la normativa comunitaria como en la nacional. Respecto de los primeros, se hará especial mención a la Directiva 2002/49/CE del Parlamento Europeo y el Consejo, de 25 de junio de 2002, sobre evaluación y gestión del ruido ambiental. Y como ejemplo de una actitud activa y decidida por promover la mejora de la calidad acústica de nuestro entrono, más allá de una mera incorporación de las disposiciones comunitarias, se mencionará la tan esperada Ley 37/2003, de 17 de noviembre, del Ruido. Todo ello, sin olvidar la importante labor de muchas Comunidades Autónomas cuya normativa ha avanzado, en muchas ocasiones, más rápido que la normativa básica estatal.

6 Como apunta Cobo Del Rosal, M.: "Sobre el insoportable "delito del ruido", en La Raz n, 18 de mayo de 2004p. 60. En relación con la dispersión normativa que existía hasta la entrada en vigor de la nueva Ley del Ruido y la importancia de la respuesta jurisdiccional ante las denuncias de los ciudadanos en materia de contaminación acústica, particularmente en los supuestos tan frecuentes de inactividad de la Administración, ver Vacas García-Alos, L.: "El derecho de las inmisiones y la protección contra la contaminación acústica», en La Leynúm. 5886, 5 de noviembre de 2003. 


\section{INCIDENCIA DEL RUIDO SOBRE LA INTEGRIDAD REAL Y EFECTIVA DE DETERMINADOS DERECHOS FUNDAMENTALES}

\section{II.1. Jurisprudencia del TEDH}

\section{II.1.A. Caso López Ostra c. España, de 9 de diciembre de 1994 y caso Guerra y otros c. Italia, de 19 de febrero de 1998}

De los dos temas que fueron objeto de estudio en el recurso de amparo que dio lugar a la STC 16/2004 —aprobada con el al voto de calidad del entonces Presidente D. Manuel Jiménez de Parga- el único que ahora interesa es si el ruido puede llegar a vulnerar determinados derechos fundamentales. El origen del presente recurso de amparo se debe a la demanda del propietario del "Pub Belfast", ubicado en Gijón, a quien el Ayuntamiento sancionó con una multa de 50.001 pesetas por infracción de la Ordenanza Municipal sobre protección contra la contaminación acústica de 10 de julio de 1992, al sobrepasar los niveles sonoros permitidos.

Al tratar esta cuestión, el Tribunal incorpora una serie de principios recogidos con anterioridad en diversas resoluciones del Tribunal Europeo de Derechos Humanos que trataban sobre la posible incidencia que el ruido tiene sobre la integridad real y efectiva de los derechos fundamentales. Todo ello, teniendo en cuenta el valor de dicha jurisprudencia para la interpretación de las normas relativas a los derechos fundamentales, en consonancia con lo preceptuado en el art.10.2 CE. Es más, nuestro Tribunal Constitucional ha llevado a cabo una interpretación extensiva de este último precepto que le ha llevado a considerar la jurisprudencia del TEDH para delimitar el contenido de los derechos ${ }^{7}$.

${ }^{7}$ En este sentido, por ejemplo, la STC 36/1984, de 3 de marzo, se basó el la jurisprudencia del Tribunal de Estrasburgo para determinar el concepto de dilaciones indebidas, y la STC 114/1984, de 29 de noviembre, puntualizó, en un asunto de posible violación de la intimidad y del derecho a la tutela judicial efectiva en un supuesto de despido, que la interpretación relevante, de acuerdo con el art. 10.2 CE es sólo la jurisdiccional del Tribunal Europeo y no la del Comité de Ministros. La doctrina del TEDH ha sido singularmente relevante en materia de escuchas telefónicas (como puede comprobarse en la STC 49/1999, de 5 de abril) o en materia de extradición (como se ve, por ejemplo, en la STC 91/2000, de 30 de marzo). 
En la jurisprudencia del TEDH, como "leading case» 8 cabe resaltar el caso López Ostra c. España, de 9 de diciembre de $1994^{9}$. Se trata de una resolución judicial adoptada en el ámbito que nos ocupa como consecuencia de una demanda presentada por la Sra. López Ostra contra España por las molestias causadas por una estación depuradora de aguas y residuos, situada próxima al domicilio de la recurrente. En aquella ocasión se reconoció que los ruidos y humos contaminantes provocados por la citada instalación vulneraban el derecho al disfrute de su domicilio en los términos del art. 8 del Convenio Europeo para la Protección de los Derechos Humanos y Libertades Fundamentales de 1950, ratificado por España el 26 de septiembre de $1979^{10}$. En su opinión, los atentados graves contra el medio ambiente pueden afectar el bienestar de una persona y privarla del disfrute de su domicilio, perjudicando su vida privada y familiar, sin necesidad de que haya que ponerse en grave peligro la salud de la interesada.

Después de examinar el comportamiento de las autoridades competentes, el Tribunal concluyó que el Estado español no supo alcanzar un justo

8 Como pronunciamientos que van anunciando esta jurisprudencia, cabe reseñar Sentencias en que el TEDH empezó a atender a la protección medioambiental por medio de la vía del derecho a un juicio justo reconocido en el art. $6 \mathrm{CEDH}$, como el caso Zimmerman y Steiner c. Suecia, de 13 de julio de 1983, y Zander c. Suecia, de 25 de noviembre de 1993; y el caso Arrondelle c. Reino Unido, que no llegó a dar lugar a pronunciamiento del TEDH porque las partes llegaron a un acuerdo, pero que se refería a graves molestias acústicas y había sido admitido por el TEDH.

9 STEDH no 1994/496, de 9 de diciembre de 1994 (López Ostra c. España). Vía. Carrillo Donaire, J. A, y Galán Vioque, R.: “¿Hacia un derecho fundamental a un medioambiente adecuado? (Comentario en torno al asunto López Ostra c. España, resuelto por la Sentencia del tribunal Europeo de Derechos Humanos de 9 diciembre 1994)", REDA, no 86, 1995; Jimena Quesada, L. y Tomás Mallén, B. S.: "El derecho al medio ambiente en el marco del Convenio Europeo de Derechos Humanos", Revista General de Derechn®o 618, 1996; Marín López, A.: "La contaminación acústica y la violación de los derechos fundamentales del hombre", Revista Interdisciplinar de Gesti $n$ Ambiental enero 2002; Ruiz Rico, G: $E I$ derecho constitucional al medio ambi,ente op. citen especial, págs. 106 y ss.; Velasco Caballero, F.: "La protección del medio ambiente ante el Tribunal Europeo de los derechos humanos (Comentario a la Sentencia del Tribunal Europeo de Derechos Humanos en el caso López Ostra c. España)", REDC, no $45,1995$.

${ }^{10}$ En virtud del artículo $8 \mathrm{CEDH}$, «1.Toda persona tiene derecho al respeto de su vida privada y familiar, de su domicilio y de su correspondencia. 2. No podrá haber injerencia de la autoridad pública en el ejercicio de este derecho, sino en tanto esta injerencia esté prevista por la ley y constituya una medida que, en una sociedad democrática, sea necesaria para la seguridad nacional, la seguridad pública, el bienestar económico del país, la defensa del orden y la prevención del delito, la protección de la salud o de la 
equilibrio entre el bienestar económico de la ciudad —como puede suponer una estación depuradora- y el del disfrute efectivo de una vida privada y familiar y del derecho al respeto de su domicilio. Todo ello, a pesar del margen de apreciación de que dispone el Estado como consecuencia de las peculiaridades nacionales, para atender el deseado equilibrio entre los intereses concurrentes del individuo y de la sociedad en su conjunto.

En el caso Guerra y otros c. Italia, de 19 de febrero de $1998^{11}$, el TEDH volvió a examinar otra posible vulneración de los derechos y libertades incluidos en el Título I del Convenio Europeo, en concreto, el derecho al respeto a la vida privada y familiar. En esta ocasión, los recurrentes eran cuarenta personas que residían aproximadamente a un kilómetro de una industria química clasificada como de alto riesgo por producir grandes cantidades de gas inflamable y otras sustancias perjudiciales. Los argumentos de la demanda fueron dos: la pasividad de las autoridades al no adoptar las medidas oportunas para reducir el riesgo y la falta de información por parte del Estado sobre las medidas a tomar en caso de accidente grave tal y como exigía la propia legislación interna.

Es interesante resaltar que, tal y como ocurre en la mayoría de estas demandas, los perjudicados no se quejaban de un acto del Estado, sino de su inactividad. Sobre este punto, el TEDH ha aclarado que el art. 8 del Convenio no se limita a prohibir determinadas injerencias por parte de una autoridad pública, sino que incluye obligaciones positivas inherentes al efectivo respeto de la vida privada y familiar de los perjudicados. De hecho, en el caso Guerra, el Tribunal quiso reseñar cómo los demandantes tuvieron que permanecer, hasta que la planta industrial paró su producción, a la espera de relevantes informaciones que les hubieran permitido sopesar el riesgo que suponía residir en esa zona.

Para terminar este somero repaso de la jurisprudencia del TEDH, quizás resulte oportuno mencionar dos sentencias relacionadas con una de las mayores fuentes productoras de contaminación acústica, en concreto, los ruidos procedentes de los grandes aeropuertos. En ambos casos, las emisiones sonoras de las aeronaves procedían del aeropuerto de Heathrow (Reino Unido) que tal y como especifica el propio Tribunal es el más ocupado en Europa y en el mundo ${ }^{12}$. Aunque los fallos sean denegatorios, las sentencias tienen un gran interés a la hora de articular una correcta y efectiva defensa de determinados valores que se encuadrarían en la denominada ter-

11 STEDH no 1998/875, de 19 de febrero de 1998 (Guerra y otros c. Italia)

12 «Es utilizado por cerca de noventa aerolíneas con conexión a ciento ochenta destinos de todo el mundo. Es el puerto líder del Reino Unido en términos de comercio visible». Vid.STEDH de 2 de octubre de 2001 (Hatton y otros c. Reino Unido). 
cera generación de los derechos fundamentales, pues en ellas resulta indudable que la contaminación acústica encaja en el art 8 del Convenio de Roma. La primera de ellas - Powel y Rayner- fue acordada por unanimidad, algo que no suele ser frecuente a la hora de resolver este tipo de cuestiones.

\section{II.1.B. Caso Powel y Rayner c. Reino Unido, de 21 de febrero de 1990}

En el caso Powel y Rayner c. Reino Unido, hay que destacar que la demanda originaria fue presentada ante la Comisión Europea de Derechos Humanos porla "Federation of Heathrow Anti-Noice बrrejemplo de organización capaz de articular el respeto de este tipo de intereses difusos. Sin embargo, en este caso, su actuación no logró frenar los evidentes intereses económicos en juego. Una vez rechazada la demanda, los Sres. Powell y Rayner decidieron seguir con el asunto por vivir a varios kilómetros del aeropuerto, en una zona especialmente afectada por los ruidos debido a su funcionamiento. De los fundamentos jurídicos presentados, la Comisión tan sólo admitió que se había violado el art 13 (derecho a un recurso efectivo), en relación con el art. 8 (derecho al respeto de la vida privada y familiar y del domicilio).

Ante dicha reclamación, el TEDH preparó su argumentación recordando todas la medidas adoptadas por las autoridades competentes para inspeccionar y reducir el ruido de los aviones en el aeropuerto y en sus alrededores, así como para reparar el daño causado a todos los afectados. Todo ello, teniendo en cuenta las normas internacionales vigentes, la evolución de la técnica aeronáutica y la diferencia en la intensidad de las molestias sufridas. Pues bien, a la vista de la descripción de las actuaciones Ilevadas a cabo por los sucesivos Gobiernos británicos para reducir y hacer más soportable este tipo de ruidos, es preciso subrayar el gran valor de la sentencia. Y es que, como advierte Martín-Retortillo, si bien el TEDH rechaza la pretensión de los demandantes, lo que hace más interesante la Sentencia desde la óptica española es la minuciosa descripción de las medidas adoptadas. En su opinión, constituye un valioso recordatorio para todos los responsables políticos y administrativos habituados a desenten-

13 «Se le llena a uno la cara de vergüenza cuando aquí es tan poco lo que se hace en relación con el ruido, viendo lo que son prácticas normales en los países de nuestro entorno. De ahí que la reflexión sobre el supuesto me parezca enormemente pedagógica para quienes en España se interesan por estos problemas». Via Martin-Retortillo, L.: «El ruido de los grandes aeropuertos en la jurisprudencia del Tribunal Europeo de Derechos Humanos", en Revista Vasca de Administraci n P boli40 septiembre-diciembre 
derse de ciertos problemas reales que tanto afectan a España ${ }^{13}$.

Tras recalcar los esfuerzos adoptados por las autoridades británicas para paliar el ruido del aeropuerto, el Tribunal utiliza, una vez más, el argumento de las peculiaridades nacionales al afirmar que «no corresponde, ciertamente, a la Comisión ni al Tribunal sustituir con su criterio el de las autoridades nacionales sobre la mejor política en este ámbito social y técnico tan difícil. En esta materia, hay que reconocer a los Estados contratantes un amplio margen de actuación ${ }^{14}$. Todo ello hará que el Tribunal justifique la limitación del derecho establecido en el art. 8 del Convenio de Roma y considere que, al no existir ninguna queja defendible, no se puede decir que no haya un derecho a un recurso de conformidad con el art.13.

En definitiva, el Tribunal distingue entre los ruidos que son «evitables" y los que no. En relación con los primeros, destaca la existencia de medidas que permiten hacerlos más soportables. De hecho, en el caso objeto de estudio, el Tribunal considera que la garantía de la protección frente al ruido puede cesar por motivos que tengan que ver con el bienestar económico del país ${ }^{15}$ siempre que se den las otras circunstancias exigidas para justificar cualquier injerencia en la calidad de vida privada y en el disfrute del domicilio. En su opinión, «no se puede pretender razonablemente que el Gobierno británico, al determinar el alcance de los medios para disminuir el ruido de las aeronaves que salen de Heathrow y allí toman tierra, ha sobrepasado su margen de apreciación o alterado el equilibrio justo que exige el artículo $8{ }^{16}$.

Ahora bien, como sugiere Martín-Retortillo, en el ámbito de la protección de derechos fundamentales lo importante no siempre es ganar, sino contribuir a que estos derechos y el sistema de valores que representan sean respetados al máximo. Al margen del resultado obtenido, no hay que olvidar que el Tribunal considera por unanimidad que la contaminación acústica

14 STEDH de 21 de febrero de 1990, epígrafe nำ4.

15 "Como lo ha señalado la Comisión en sus resoluciones sobre la admisibilidad, la existencia de grandes aeropuertos internacionales, incluso en zonas urbanas muy pobladas, y el incremento del empleo de los aviones a reacción, se han hecho indudablemente necesarios para el bienestar económico del país. Según estadísticas no discutidas facilitadas por el Gobierno, el aeropuerto de Heathrow, uno de los más utilizados del mundo, tiene extraordinaria importancia en el comercio y las comunicaciones internacionales, así como en la economía del Reino Unido. Los propios demandantes reconocen que la explotación de un aeropuerto de estas condiciones persigue un fin legítimo y que no se puede suprimir totalmente las repercusiones desfavorables en el ambiente." STEDH de 21 de febrero de 1990, epígrafe $\mathrm{n}^{\circ} 42$.

${ }^{16}$ STEDH de 21 de febrero de 1990, epígrafe $\mathrm{n}^{\circ} 45$.

17 Vid.Martín-Retortillo, L.: “El ruido de los grandes aeropuertos....», op. citp, 120. 
encaja en el artículo 8 del Convenio (vida privada y familiar y domicilio) ${ }^{17}$.

\section{II.1.C. Caso Hatton y otros c. Reino Unido: 2 de octubre de 2001 y 8 de julio de 2003}

Con motivo de la Sentencia de 2 de octubre de 2001 en el caso Hatton y otros c. Reino Unido ${ }^{18}$, el Tribunal se decide con mayor claridad por la protección contra la contaminación acústica dentro de los derechos humanos más clásicos. En ella, vuelve a reconocer la importancia del factor económico y la existencia de un cierto margen de apreciación a favor de la Administración a la hora de determinar las medidas para minimizar los efectos nocivos del ruido nocturno. Pero, al mismo tiempo, insiste en la obligación de los Estados de minimizar hasta donde sea posible la injerencia en el ejercicio de los derechos garantizados por el artículo 8, buscando otras soluciones alternativas menos gravosas y esforzándose por alcanzar sus fines de la manera más respetuosa con los derechos humanos. A partir de ahí su objetivo se basa en averiguar si el Gobierno demandado respetó sus obligaciones positivas para asegurar el disfrute efectivo de los derechos contemplados en el Convenio de Roma como parte del mismo, al permitir el incremento de vuelos nocturnos de aviones como consecuencia de la aplicación de un nuevo sistema de cuotas de ruido (Noise Quota Scherte, aunque ni el aeropuerto ni los aviones eran propiedad del Estado.

Pues bien, el TEDH entiende que, en este caso, el Gobierno Británico no respetó el justo equilibrio entre los intereses en juego al no existir «ningún intento serio de evaluar el alcance o impacto de las injerencias acústicas en los hábitos de sueño de los demandantes y, en general, en ausencia de un completo estudio previo con el fin de encontrar la solución menos gravosa con respecto a los derechos humanos» 20 . A su juicio, las medidas gubernamentales que fueron adoptadas para respaldar el incremento de ruido nocturno fueron insuficientes; de ahí que considere viola-

18 STEDH no 2001/567, de 2 de octubre de 2001 (Hatton y otros c. Reino Unido)

${ }^{19}$ En virtud del nuevo sistema de 1993, que venía a reemplazar a las medidas adoptadas en 1988 por un período de 5 años, se asignó una porción de cuota a cada avión dependiendo si eran más o menos ruidosos y se atribuyó al aeropuerto un número de puntos de cuota según la época del año y dependiendo si se trataba de un período diurno o nocturno. Con base en esos márgenes, los movimientos de aviones tenían que mantenerse dentro del total de puntos de cuota permitida. Se fomentaba la utilización de aviones silenciosos ya que cuanto más ruidoso era un avión, más importante era la parte de cuota que se absorbía en cada momento.

20 STEDH de 2 de octubre de 2001, epígrafe ํㅜ 106. 
do el disfrute efectivo del derecho de los recurrentes al respeto de sus vidas privadas y familiares y de sus domicilios. A diferencia de otros fallos, se basa en el especial significado que hoy se otorga a la protección medioambiental para considerar que la mera referencia al bienestar económico del país ya no es suficiente.

Sin embargo, tras el reenvío de la cuestión ante la Gran Sala a petición del Gobierno demandado el 8 de julio de 2003, el TEDH —por doce votos contra cinco- consideró que no hubo violación del art. 8 del Convenio de Roma. Antes de analizar estas polémicas conclusiones que revisan algunos aspectos esenciales de la sentencia inicial y contrastan con la clara sensibilidad que existe hoy en día respecto de los ruidos, ha de destacarse lo poco frecuente que resulta este tipo de remisión a la Gran Sala. De hecho, de conformidad con el artículo 43 del Convenio de Roma es una posibilidad prevista para casos excepcionales, en los que sólo se aceptará si el asunto plantea una cuestión grave relativa a la interpretación o a la aplicación del Convenio o de sus Protocolos o una cuestión grave de alcance general.

Una vez más, como elemento de juicio fundamental, el Tribunal analiza la existencia o no de un equilibrio equitativo entre los intereses en conflicto, de una parte, el derecho de las personas de ver respetada su vida privada y su domicilio y, de otra parte, los intereses concurrentes de la sociedad en su conjunto. A partir de ahí, revisa dos de las cuestiones que fueron fundamentales para determinar la violación del Convenio en la Sentencia de 2 de octubre de 2001. Por un lado, considera razonable presumir el alcance económico del pretendido interés general en mantener los vuelos nocturnos de aviones desde el punto de vista de la economía del país. En este sentido, recuerda que el Estado está legitimado para restringir el derecho al respeto de la vida privada y familiar cuando sea necesario para tomar en consideración el bienestar económico de la sociedad en su conjunto y la protección de los derechos y libertades de otros, como establece el artículo 8.2 del Convenio ${ }^{21}$.

Por otro lado, estima suficientes las medidas adoptadas por el

${ }^{21}$ Aunque los informes elaborados antes y después de la adopción del Plan de 1993 no incluyen ninguna indicación precisa sobre el coste económico de la supresión de vuelos nocturnos concretos, el TEDH juzga fácilmente admisible el interés económico que existe en mantener este tipo de servicio. Así, por ejemplo, determinados vuelos procedentes de Extremo Oriente tan sólo podrían llegar de día a Londres, si despegaran muy tarde por la noche, lo que perjudica considerablemente a los pasajeros y conlleva una pérdida de competitividad. Todo ello, sin olvidar que la explotación de las compañías aéreas está sujeta a importantes limitaciones en el marco del nuevo sistema de cuotas de 1993. Via.STEDH de 8 de julio de 2003, epígrafe $\mathrm{n}^{\circ} 126$. 
Gobierno británico para minimizar los efectos del ruido en el aeropuerto. La Gran Sala señala que, a diferencia de los asuntos anteriores en los que problemas medioambientales habían llevado al TEDH a concluir que se había producido una violación del artículo 8 del Convenio, en el presente caso no había habido inobservancia por las autoridades nacionales de ciertos aspectos de Derecho interno. En su opinión, las autoridades competentes actuaron correctamente de conformidad con el margen de apreciación que disponen y su mejor posición para ponderar los intereses en conflicto. De hecho, el nuevo sistema de cuotas quedaba sometido al control permanente de la Dirección del aeropuerto y del Comité consultivo de vigilancia del ruido, en cuyo seno estarían representadas las colectividades locales situadas en las proximidades del aeropuerto. El plan de 1993 fue precedido por una serie de investigaciones realizadas, entre las que cabe destacar el "Informe de un estudio de terreno relativo al ruido ocasionado por las aeronaves y los trastornos del sueño" publicado en diciembre de 1992. Entre sus conclusiones, el informe afirmaba que la mayoría de las personas residentes cerca del conflictivo lugar no corrían el riesgo de ver su sueño gravemente perturbado por estas agresiones acústicas y que sólo un pequeño porcentaje (2-3\%) presentaba una sensibilidad especial a estas molestias ${ }^{22}$. Además, el TEDH destaca que los demandantes y personas que se encontraban en situaciones análogas tuvieron acceso al documento de consulta publicado a principios de 1993 en el que se daba a conocer el alcance del nuevo sistema de cuotas. Por tanto, tuvieron la facultad de formular todas las observaciones que juzgaron oportunas. Si los comentarios de estas personas- especialmente bien situadas para hacer este tipo de observaciones al ser miembros o ex miembros de

HACAN (Heathrow Association for the Control of Aircrafuonseise) hubieran tenido en cuenta, habrían podido impugnar las decisiones ulteriores o el plan mismo ante los Tribunales ${ }^{23}$.

La Sentencia plantea dudas interpretativas. Podría estimarse que, a diferencia de la sentencia inicial, el TEDH prioriza otros intereses sobre la protección medioambiental. En concreto, que no otorga el mismo peso al hecho de estar en presencia de un aspecto íntimo del derecho a la vida privada y

22 STEDH de 8 de julio de 2003, epígrafe no 35. EI TEDH estima que cuando este número tan restringido de personas que padecen especialmente una medida general, puede mudarse sin sufrir pérdidas financieras, ello un elemento de peso en la apreciación del carácter globalmente razonable de la medida cuestionada. A este respecto, la Gran Sala destaca que los demandantes no impugnaron realmente la afirmación del Gobierno según la cual el ruido nocturno no había tenido incidencia negativa sobre el precio de los inmuebles en los lugares donde residían (epígrafe $\mathrm{n}^{\circ} 127$ ).

${ }^{23}$ STEDH de 8 de julio de 2003, epígrafe $n^{\circ} 128$. 
familiar y al respeto del domicilio, como es el hecho de poder dormir y descansar por la noche, con la consiguiente obligación por parte de las autoridades competentes de justificar convincentemente la necesidad de una injerencia en tales derechos y la imposibilidad de utilizar otras medidas menos gravosas. Acaso podría considerarse que la Gran Sala se apoya más en las relevantes repercusiones económicas para justificar las actuaciones emprendidas por el Gobierno tras el Plan de 1993 que, tal y como reconoce el propio Tribunal, repercutió negativamente en la calidad de vida privada de los recurrentes y, por tanto, en los derechos reconocidos en el artículo 8, que en el especial significado que hoy se otorga a la protección medioambiental ${ }^{24}$. Pero parece más exacto interpretar que lo esencial es que el medio ambiente sigue protegido, con independencia de que se insista más o menos en la importancia económica o en los derechos de los individuos. Así parece entenderlo el propio Tribunal de Estrasburgo y el nuestro, que en la STC 16/2004, de 23 de febrero, FJ 3, cita esta Sentencia del TEDH junto a las anteriores del mismo Tribunal en la materia, diciendo tan solo que esta última introduce algún matiz que no llega a especificar.

Sin embargo, según se razona en uno de los votos particulares disidentes que integran la Sentencia de la Gran Sala, se trata de un fallo polémico e incluso cuestionable a la vista de la evolución que, hasta ese momento, había experimentado la jurisprudencia del TEDH en su orientación hacia la protección directa del medio ambiente y, en especial, en los supuestos de contaminación acústica. En efecto, en el resto de los casos que se han mencionado con anterioridad, el TEDH había tenido muy en cuenta las condiciones de vida actuales, tomando en consideración nuevas formas de injerencia en el ejercicio de los derechos que no fueron previstas en el Convenio de 1950. Para los jueces Costa, Ress, Türmen, Zupancic y Steiner, la interpretación evolutiva hecha por la Comisión y el TEDH de las diferentes exigencias del Convenio han sido generalmente "progresistas" al ampliar gradualmente la protección de los derechos y libertades garantizados por el Convenio con el fin de crear el «orden público europeo». En términos similares se ha

${ }^{24}$ STEDH de 8 de julio de 2003, epígrafe no 118.

25 Loperena Rota, D.: «El medio ambiente en el Tribunal Europeo de Derechos Humanos", en Repertorio Aranzadi del Tribunal Constntúna:ibo/z003. De conformidad con el autor, el TEDH afrontó en su momento este asunto con una decisión y una lucidez que, desgraciadamente, estamos viendo desaparecer. Porque si en los años ochenta y noventa, encontramos casos en que se condena a los Estados por no respetar los derechos ambientales de sus ciudadanos, el nuevo siglo nos está proporcionando alguna sentencia de sentido involucionista. Entre los casos en los que se priorizan otros intereses sobre la protección ambiental, incluye la reciente sentencia Hatton c. Reino Unido de la Gran Sala. 
pronunciado entre nosotros algún autor ${ }^{25}$, para quien los más de cincuenta años del Convenio son demasiados años para que un texto pueda mantenerse joven. De ahí que el Tribunal haya aplicado el principio jurídico de adecuar la interpretación del mismo a las cambiantes circunstancias sociales. En su opinión, entre las nuevas percepciones jurídicas menos fáciles de abordar, nos encontramos con el problema ambiental y la relación jurídica del ser humano con el medio ambiente con base en un derecho humano no reconocido formalmente en el Convenio de 1950. En este punto, no hay que olvidar que la Carta de los Derechos Fundamentales del Tratado por el que se establece una Constitución para Europea ${ }^{26}$ garantiza la protección del medio ambiente en su artículo II-97. En virtud del nuevo Tratado Constitucional, firmado en Roma el 29 de octubre de 2004, "en las políticas de la Unión se integrarán y garantizarán, conforme al principio de desarrollo sostenible, un nivel elevado de protección del medio ambiente y la mejora de su calidad».

Pero, al margen de esta última Sentencia, considerada por algunos como "regresiva» 27 , es preciso valorar la evolución experimentada en la jurisprudencia europea hacia una protección directa del medio ambiente sonoro y su decisiva influencia en la doctrina de nuestro Tribunal Constitucional. El razonamiento seguido por el Tribunal Europeo al aplicar el principio de proporcionalidad para determinar la compatibilidad o no de una injerencia en los derechos garantizados en el Convenio, ha sido determinante por ser más progresista y acorde con una interpretación "pro víctima» en los órganos judiciales protectores de los derechos fundamentales ${ }^{28}$.

\section{II.1.D. Caso Moreno Gómez c. España, de 16 de noviembre de 2004}

${ }^{26}$ Disponible en Internet, en la página web, www.constitucioneuropea.es

27 Vid.Cacho Sánchez, Y.: "Los ruidos, los derechos humanos medioambientales y el derecho al respeto a la vida privada y familiar: asunto Hatton y otros c. Reino Unido", en Revista General de Derecho Eurcxúm. 2, octubre 2003.

${ }^{28}$ Como señala García San José, D.: «Ruido nocturno e insomnio: los derechos a la vida privada y familiar y al respeto del domicilio frente al interés general de los vuelos de aviones durante la noche. Comentario a la Sentencia del Tribunal Europeo de Derechos Humanos de 2 de octubre de 2001, en el caso Hatton y otrocontra Reino

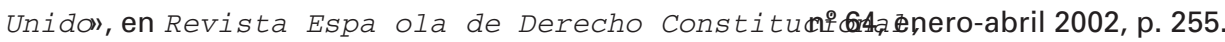

${ }^{29}$ En sentido similar, en el caso Surugiu c. Rumanía, de 20 de abril de 2004, relativo a diversas molestias, entre las cuales, destacaba la entrada de terceras personas en el patio de la casa del recurrente y el vertido por estas personas de varias carretillas de basura delante de la puerta y bajo las ventanas de la casa, el Tribunal estimó que dichas molestias constituían injerencias repetidas en el ejercicio, por parte del recurrente, de su derecho al respeto del domicilio y concluyó la aplicabilidad del art. 8 del Convenio. 
Esta tendencia se confirma en el caso Moreno Gómez c. España, de 16 de noviembre de $2004^{29}$. La Sentencia parte de que el asunto no se refiere a una injerencia de las autoridades públicas en el ejercicio del derecho al respeto del domicilio, sino que afecta a la inactividad de las autoridades para hacer cesar las vulneraciones causadas por terceras personas al derecho invocado por la recurrente. El Tribunal constata que la recurrente vivía en una zona en la que el ruido nocturno era innegable, lo que con toda evidencia provocaba perturbaciones en la vida cotidiana de la recurrente, sobre todo el fin de semana, lo que hace que el Tribunal se plantee si las molestias sonoras sobrepasaban o no el umbral mínimo de gravedad para constituir violación del art. 8 del Convenio.

A tal propósito el Tribunal recuerda que las autoridades municipales calificaron la zona en que la recurrente habitaba como "acústicamente saturada" de conformidad con la resolución municipal de 27 de diciembre de 1996, esto es, como una zona que sufre un impacto sonoro elevado que constituye fuente de agresión importante para sus habitantes, a lo que añade que los propios servicios municipales habían constatado en varias ocasiones que se sobrepasaban los niveles máximos de ruido. Habida cuenta de la intensidad de las molestias sonoras, por encima de los niveles autorizados y durante las horas nocturnas, y de que dichas molestias se habían repetido durante varios años, se concluye la afectación a los derechos protegidos por el art. 8 del Convenio.

Cierto es, añade el Tribunal, que la Administración municipal de Valencia adoptó en el ejercicio de sus competencias medidas en principio adecuadas, como la aprobación de la ordenanza de ruidos y vibraciones. Pero durante el periodo analizado la propia Administración había tolerado la inobservancia reiterada de la regulación que ella misma había aprobado. Por lo que se concluye que el Estado demandado había incumplido su obligación positiva de garantizar el derecho de la recurrente al respeto de su domicilio y su vida privada, vulnerando el art. 8 del Convenio.

\section{II.2. Jurisprudencia del Tribunal Constitucional}

\section{II.2.A. STC 119/2001, de 24 de mayo}

La recepción de la doctrina del TEDH tiene lugar con la STC 119/2001,

${ }^{30}$ BOE no 137 (suplemento), de 8 de junio.

${ }^{31}$ En ella, nuestro Alto Tribunal reitera el valor que, en virtud del a.10.2 CE, recono- 
de 24 de mayo ${ }^{30}$ que encuadra el ruido en el marco de los derechos fundamentales, aunque resulta más cautelosa que las sentencias del TEDH ${ }^{31}$.

El fallo de esta Sentencia es denegatorio del recurso de amparo interpuesto por una señora que vivía en una zona acústicamente saturada y que se sentía indefensa ante la pasividad del Ayuntamiento frente al excesivo ruido. Entre otros argumentos denegatorios, el Tribunal Constitucional recurre a la manifiesta debilidad del material probatorio "toda vez que no se ha acreditado que nos encontremos ante la existencia de una lesión real y efectiva de los derechos fundamentales aducidos imputable al Ayuntamiento de Valencia, requisito inexcusable habida cuenta del carácter subjetivo de este remedio para la protección de los derechos fundamentales» ${ }^{32}$. El hecho de que el Tribunal Constitucional se posicione en el criterio objetivo del perjuicio que haya podido sufrir la demandante -y que, en consecuencia, habrá de probar- ha sido objeto de algunas críticas por parte de la doctrina al considerar que el Tribunal Constitucional se aparta del criterio de calidad seguido por el TEDH respecto de las injerencias acústicas, esto es, examinar la naturaleza del derecho afectado y su importancia para el particular. Para el TEDH, advierte García San José, tratándose de los derechos al respeto del domicilio, de la vida privada y familiar, "los Estados están obligados a minimizar, tanto como les sea posible, las injerencias en estos derechos, tratando de encontrar soluciones alternativas $y$, en general, buscando conseguir sus fines de la manera menos gravosa para los derechos humanos» ${ }^{33}$.

En lo que respecta a la vulneración de los derechos fundamentales, cabe elogiar los argumentos utilizados por el Tribunal Constitucional - tras hacer mención a la doctrina constitucional establecida hasta ese momento (en especial, STC 199/1996, de 3 de diciembre)- para conectar el ruido con el derecho a la intimidad y la protección del domicilio, así como con el derecho a la integridad física y moral. Por el contrario, el Tribunal Constitucional rechaza entrar en el problema de la degradación del medio ambiente a causa del ruido por ser una cuestión reconducible a la esfera

ce a la doctrina del TEDH en su interpretación y tutela de los derechos fundamentales. En cualquier caso, advierte que ello no debe suponer una "traslación mimética" de su doctrina que ignore tanto las diferencias normativas existentes entre la CE y el Convenio Europeo, como la necesidad de acotar el ámbito del recurso de amparo a sus estrictos términos.

32 STC 119/2001 de 24 de mayo (FJ no 7).

33 Vid.García San José, D., op. ci tp. 257. 
propia del art. 45, al margen, por tanto, de los derechos susceptibles de amparo.

Por lo que se refiere a la protección contra el ruido en el ámbito de actuación del art. 15 CE, el Tribunal Constitucional exige dos circunstancias para admitir una vulneración del derecho a la integridad física y moral: 1) que los niveles de saturación acústica que deba soportar una persona rebasen el umbral a partir del cual se ponga en peligro grave e inmediato la salud, 2) que se haya producido como consecuencia de una acción u omisión de los poderes públicos. Este es otro de los ejemplos que denotan que nuestro Tribunal Constitucional resulta ser más cauteloso que el Tribunal Europeo, especialmente en las SSTEDH de 9 de diciembre de 1994, caso López Ostra, y de 19 de febrero de 1998, caso Guerra y otros. Tal y como se explicó en su momento, en dichas resoluciones se advierte que, en determinados casos de especial gravedad, ciertos daños ambientales aun cuando no pongan en peligro la salud de las peypureden atentar contra su derecho al respeto de su vida privada y familiar, privándola del disfrute de su domicilio, en los términos del art. 8.1 del Convenio de Roma. El Magistrado D. Manuel Jiménez de Parga en su voto particular se pronuncia en la misma línea, al rechazar que la vulneración del derecho a la integridad física exija un peligro grave e inmediato para la salud de las personas. Entiende que basta la existencia de cualquier efecto nocivo.

Respecto a los derechos del art. $18 \mathrm{CE}$, nuestro Tribunal reitera la idea de "ruidos evitables" tal y como hiciera el TEDH. A su juicio, "una exposición prolongada a unos determinados niveles de ruido, que puedan objetivamente calificarse como evitables e insoportables, ha de merecer la protección dispensada al derecho fundamental a la intimidad personal y familiar, en el ámbito domiciliario, en la medida en que impidan o dificulten gravemente el libre desarrollo de la personalidad, siempre y cuando la lesión o menoscabo provenga de actos u omisiones de entes públicos a los que sea imputable la lesión producida» ${ }^{34}$. En definitiva, el Tribunal Constitucional condiciona los conceptos de intimidad personal, libre desarrollo de la personalidad e inviolabilidad del domicilio ${ }^{35}$.

Otro aspecto interesante de la Sentencia es el empeño del Tribunal

${ }^{34}$ FJ 6 de la STC 119/2001.

${ }^{35}$ Sin embargo, el Magistrado Jiménez de Parga en su voto particular no comparte la idea de vincular el libre desarrollo de la personalidad al ámbito domiciliario. En su opinión, el ruido como fenómeno unitario tiene efectos nocivos sobre la salud, con independencia de dónde y cómo se produzca. 
Constitucional en recalcar la dimensión positiva de los derechos fundamentales afectados, teniendo en cuenta que nuestra Constitución consagra derechos reales y efectivos. En base a la efectividad real e inmediata que garantiza nuestra Norma Suprema, se hace imprescindible asegurar su protección no sólo frente a las injerencias tradicionales, sino también frente a riesgos que puedan surgir en una sociedad tecnológicamente avanzada tal y como ocurre con el ruido que "puede llegar a representar un factor psicopatógeno destacado en nuestra sociedad y una fuente permanente de perturbación de la calidad de vida de los ciudadanos»" ${ }^{36}$. En este sentido, recurre a las directrices marcadas por la Organización Mundial de la Salud sobre el ruido ambiental, que ponen de manifiesto las consecuencias de una exposición prolongada a un nivel elevado de ruido, tanto sobre la salud de la personas como sobre la conducta social.

De los dos votos particulares que completan la Sentencia, cabe destacar asimismo la crítica que se hace a la dejadez e inactividad de las autoridades responsables, así como el interés en recalcar el contenido ambiental de los derechos fundamentales y el valor que habría que dar al contenido subjetivo de algunos derechos no susceptibles de amparo, como el derecho al medio ambiente del art. 45. En opinión del Magistrado Jiménez de Parga hubiese resultado conveniente reivindicar esa vertiente subjetiva del art. 45.1 CE pues "la historia demuestra, con harta frecuencia, que el Derecho evoluciona hacia la consecución de mayores cotas de bienestar y libertad gracias sobre todo a los esfuerzos de los ciudadanos que tratan de hacer valer sus derechos frente a la pasividad de los poderes públicos. Creo que este Tribunal, en el presente caso, podría haber contribuido a aportar unos instrumentos que fecundaran esa labor de lucha por el Derecho y por la mejora de la calidad de vida, que también es, no se olvide, un valor constitucional (art. $45 \mathrm{CE}) \wedge^{37}$.

En efecto, expresamente unido al desarrollo de la persona y a la cali-

${ }^{36}$ FJ 5 de la STC 119/2001.

37 Apartado segundo del Voto Particular nำ1 de la STC 119/2001. En términos similares Parejo Alonso propugna que "a través del deber estatal de acción y resultado, los contenidos principales del Capítulo III del Título I CE y, concretamente, el medio ambiente adecuado se "subjetivizan" en la medida en que los derechos proclamados con motivo del establecimiento de aquéllos y, en particular, el derecho a disfrutar de un medio ambiente adecuado son parte del contenido constitucionalmente declarado de los derechos constitucionales, incluso de los fundamentales-libertades públicas de la Sección $1^{\text {a }}$ del Capítulo II del Título I CE». Citado en Vacas García-Alos, L.: "El derecho de las inmisiones y la protección contra la contaminación acústica", en La Ley,núm. 5886, 5 de noviembre de 2003, p. 2. 
dad de vida, se podría pensar en el art. $45 \mathrm{CE}$, que contempla el derecho a disfrutar de un medio ambiente adecuado y el correspondiente deber de conservarlo. Del encuadramiento de este último artículo en el Capítulo III del Título I de la Constitución, se deduce la responsabilidad constitucional del Estado social y democrático de Derecho de dar cobertura a estas nuevas necesidades. Al igual que todos los principios rectores, se podría decir que esa responsabilidad acerca de su debida conservación depende del grado de sensibilización que muestren los órganos competentes en la evolución del Estado en el ámbito social. Desgraciadamente, lo que la realidad ha demostrado con nitidez es la escasa eficacia real de la tutela frente al ruido desde esta perspectiva al no contar con las vías procesales de defensa de los derechos fundamentales. Según se dijo en su momento, la necesidad de proteger al ciudadano frente a la inactividad o ineficiencia de las Administraciones Públicas ha llevado a los tribunales a encuadrar la materia en el campo de los derechos fundamentales, con el aplauso casi general de la doctrina, aun sin faltar voces críticas.

\section{II.2.B. STC 16/2004, de 23 de febrero}

En esta ocasión, el Tribunal Constitucional vuelve a pronunciarse sobre cuándo el ruido afecta a los derechos fundamentales, sirviéndose de los mismos argumentos que han sido objeto de estudio en la STC 119/2001. En concreto, su posible conexión con la integridad física y moral (art.15 CE), la intimidad personal y familiar (art.18.1 CE) y la inviolabilidad del domicilio (art. 18.2 CE). Siguiendo, una vez más, al verdadero pionero en el intento de encuadrar el ruido desde el punto de vista de los derechos fundamentales y los principios constitucionales, se trata de "la eterna lucha por la búsqueda de los títulos jurídicos» ${ }^{38}$. A este respecto, es evidente la necesidad de acudir a los genuinos derechos fundamentales, con su fuerza vinculante y con sus especiales modalidades de garantía.

Como ya hiciera en la STC 119/2001, el Tribunal Constitucional vuelve a recalcar la dimensión positiva de los derechos fundamentales afectados, teniendo en cuenta que nuestra Constitución consagra derechos reales y efectivos que vinculan a todos los poderes públicos. De dicha vinculación no solamente hay que deducir la obligación negativa del Estado de no lesionar la esfera individual o institucional protegida por los derechos

38 Vid.Martín-Retortillo Baquer, L.: «El ruido de los grandes aeropuertos en la jurisprudencia del Tribunal Europeo de Derechos Humanos", op. ci, tp. 104. 
fundamentales, sino también la obligación positiva de contribuir a la efectividad de tales derechos y de los valores que representan, aun cuando no exista una pretensión subjetiva por parte del ciudadano. Como ya se dijo en la STC 53/1985, de 11 de abril, ello obliga especialmente al legislador, quien recibe de los derechos fundamentales los impulsos y líneas directivas, obligación que adquiere especial relevancia allí donde un derecho o valor fundamental quedaría vacío de no establecerse los supuestos para su defensa. En este sentido, el Tribunal hace mención a la tan esperada y reclamada Ley 37/2003, de 17 de noviembre, del Ruido. De ella, destaca su Preámbulo para recordar la relación que existe entre la protección constitucional contra la contaminación acústica y el mandato también constitucional de proteger la salud y el medio ambiente, por un lado, $y$, por el otro, el derecho a la intimidad personal y familiar. Como afirma Jiménez de Parga, en el ámbito del amparo los principios rectores de política económica y social son de mención pertinente cuando aparecen como derechos conexos con otro derecho fundamental ${ }^{39}$.

\section{II.2.C. Consideraciones sobre el tratamiento jurispruden- cial del ruido desde la perspectiva de los derechos fundamentales: los derechos fundamentales «no escritos"}

Los principios recogidos con anterioridad en las sentencias del TEDH y del propio Tribunal Constitucional han sido determinantes para conseguir un tratamiento del ruido desde la perspectiva de los derechos fundamentales. Ahora bien, no hay que olvidar que la mayoría de las sentencias han sido fruto de polémicas deliberaciones — dando lugar a numerosos votos particulares - por la dificultad de encajar nítidamente la tutela frente al ruido en el ámbito de los derechos fundamentales típicos. En definitiva, se plantea la controvertida cuestión del reconocimiento constitucional de nuevos derechos fundamentales amparables ante el Tribunal Constitucional como respuesta a las nuevas realidades jurídicas. Y es que, esa eterna lucha por la búsqueda de los títulos jurídicos nos lleva a constatar cómo el sistema jurídico sufre con frecuencia "una tensión expansiva que fuerza a hacer más elásticos los conceptos jurídicos, construidos acaso

39 Vid. Jiménez de Parga, M.: "Veintitrés años de jurisprudencia del Tribunal Constitucional sobre derechos fundamentales", en Revista de Derecho Pol tico de la UNED no 58-59, 2003-2004, p. 157

40 Vid.Martín-Retortillo Baquer, L.: «El ruido de los grandes aeropuertos ..., op. cł p. 
en su momento con mayor rigidez y dureza» ${ }^{40}$. Según se adelantó en su momento, la posibilidad de reconocer nuevos derechos constitucionales no escritos depende en gran medida del propio texto constitucional que debe ofrecer un fundamento jurídico válido para proteger este tipo de derechos no mencionados expresamente, así como de la interpretación del Tribunal Constitucional al respecto ${ }^{41}$.

En cuanto al posible fundamento jurídico-constitucional de los derechos no escritos, cabe distinguir tres, que son compatibles entre sít2: 1) "lista abierta" de derechos que permite un reconocimiento de nuevos derechos no escritos y dota de mayor discrecionalidad a los tribunales que aplican la Constitución para determinar qué nuevos derechos alcanzarían reconocimiento constitucional; este tipo de Constitución suele contener un precepto que de alguna forma advierte que los derechos mencionados en

${ }^{41}$ En opinión de Revenga Sánchez, la postura de nuestro Tribunal Constitucional en materia de derechos nuevos es de meridiana claridad: "no hay lugar para ellos; o no lo hay, al menos, desde la óptica a partir de la cual ejerce el Tribunal su función de salvaguardia última de los derechos tenidos en la Constitución por $m s$ fundamentales. Cierta resistencia (típica de la voluntad refrendadale la justicia constitucional) a llevar los razonamientos más allá de lo imprescindible para resolver el caso, y el temor (bien fundado, por cierto) a alentar recursos de amparo destinados a no pasar el filtro de la admisión a trámite, se conjuga para desterrarlos». En este punto, el autor se apoya en una jurisprudencia que califica de restrictiva, pero en la que tampoco faltan obiter dicta que atribuyen el carácter de "constitucionales" o "subjetivos" (pero no fundamentales) a manifestaciones específicas de una genérica libertad de acción, que se asemejan bastante a lo que podrían ser tenidos por derechos nuevos en otros sistemas de nuestro entorno." Así, por ejemplo, menciona las SSTC 53/1985, 89/1987, 37/1989, 215/1994, 57/1994, 48/1996 o 207/1996). Vid.Revenga Sánchez, M.: «Sobre (viejos) modelos de justicia constitucional y creación de (nuevos) derechos", en Revista de Derecho Constitucion 19 64, enero-abril 2002.

42 Seguimos en este punto a Díaz Revorio, F.J.: "Tribunal Constitucional y Derechos Constitucionales "no escritos», en Espin Templado, E. y Díaz Revorio, F.J., La Justicia Constitucional en el Estado democrTiránolo Blanch, Valencia, 2000, págs. 233 y ss.

43 Dice Jiménez de Parga, M. («Veintitrés años de jurisprudencia del Tribunal Constitucional sobre derechos fundamentales", en Revista de Derecho Pol tico de la UNED, no 58-59, 2003-2004, págs. 163-164): «se olvidó, o no quiso recogerse [en nuestra Constitución] la norma sabia contenida en la Enmienda IX de la Constitución norteamericana. Se dejó dicho allí: "la enumeración que se hace en esta Constitución no deberá interpretarse como denegación o menoscabo de otros derechos que conserva el pueblo".

El art. 17 de la Constitución de Portugal, revisado en 1982, dice que "el régimen de derechos, libertades y garantías se aplica a los enunciados en el Título II y a los derechos 
el texto no agotan el catálogo de los que quedan reconocidos en ella (por ejemplo, la Enmienda IX de la Constitución norteamericana, el art. 17 Constitución portuguesa o el art. 33 de la Constitución argentina) ${ }^{43}$; 2) reconocimiento expreso de determinados valores generales, y muy especialmente la libertad y la dignidad, que pueden actuar como fuente de derechos no escritos, por su formulación genérica capaz de dar cobertura prácticamente a cualquier nuevo derecho. Su configuración como derecho autónomo depende sobre todo de que la jurisprudencia se haya pronunciado sobre la "norma general de libertad" que comprende todas las manifestaciones de la autonomía personal o de la libertad general de actuación, lo que suele ocurrir como consecuencia de una nueva necesidad o exigencia socialmente reconocida; 3) reconocimiento particular, al hacer derivar un nuevo derecho de un derecho constitucional expresamente reconocido con un amplio contenido.

Existen supuestos que se resisten a ser clasificados en alguno de los apartados anteriores. Es el caso de la República Federal Alemana, donde no se reconocen derechos fundamentales "no escritos" con tal denominación con base en la Ley Fundamental. Pero el Tribunal Constitucional Federal alemán (BVerfG) ha reconocido un "derecho general de la personalidad» - «allgemeines Persönlichkeitsrecht»— basándose en el artículo 1 párr. 1 de la Ley Fundamental (dignidad humana) y en el artículo 2 párr. 1 (la llamada «libertad general de actuación individual» — «allgemeine Handlungsfreiheit») ${ }^{44}$.

De allí, el BVerfG ha desarrollado sucesivamente ulteriores sub-cate-

fundamentales de naturaleza análoga». Se habla por ello en el país vecino de derechos fundamentales en sentido material y de derechos fundamentales en sentido formal, así como de derechos extraconstitucionales o de derechos fundamentales atípicos. En definitiva lo que se pretende subrayar es que la Constitución incluye un catálogo inacabado, que ha de ser completado si otros derechos reclaman, con exigencias razonables, la tutela constitucional.

En Argentina, antes de la última reforma, la Constitución ya contenía un artículo, el 33, del siguiente tenor: "las declaraciones, derechos y garantías que enumera la Constitución no serán entendidos como negación de otros derechos y garantías no enumerados; pero que nacen del principio de la soberanía del pueblo y de la forma republicana de gobierno". Si pasamos por alto esta concesión a "la forma republicana", tan cara a los franceses y que resulta desmentida con la presente Monarquía española, lo que nos importa consignar es que la doctrina argentina consideró los derechos extraconstitucionales antes de 1994. Fueron catalogados derechos explícitos, derechos no enumerados provenientes del derecho natural y derechos imputados o creados por la jurisprudencia».

44 Vid.Pieroth, Bodo y Schlink, Bernhard, Grundrechte Staatsrech $19^{a}$ ed., 2003, págs. 85-88.

45 BVerfGE 78, 38, 49 
gorías de aquel "derecho general de la personalidad", concretamente con respecto a: 1) la autodeterminación del individuo, como por ejemplo el derecho al propio nombre ${ }^{45}$ o sexo ${ }^{46} ; 2$ la la protección de la esfera privada o íntima, especialmente en lo referido a la protección de datos personales ${ }^{47}$, que después desembocó en: 3) un «derecho general a la autodeterminación informativa" (Grundrecht auf informationelle Selbstbestimmung ${ }^{48}$ ) del cual se deduce también la protección de la imagen propia ("Recht am eigenen Bild") y del honor de la persona ("Schutz der persönlichen Ehre») y especialmente la debida protección contra la prensa ("paparazzis»)49.

A la vista de lo anterior, quizás resulte interesante analizar cómo ha respondido nuestra jurisprudencia constitucional a esas nuevas realidades jurídicas con el fin de reconocer intereses esenciales de los ciudadanos que hasta el momento no contaban con una protección, al menos explícita y concreta. En concreto, qué fundamentos jurídico-constitucionales ha utilizado nuestro Alto Tribunal para reconocer derechos no escritos en una tabla de derechos tan avanzada y extensa como la nuestra. A este respecto, es preciso advertir que la labor de nuestro Tribunal Constitucional no ha sido tan intensa como la que se ha llevado a cabo en otros sistemas. Como señala Revenga Sánchez, cuanto mayor sea el retraso o déficit generacional de derechos reconocidos en el texto constitucional, mayor presión para el reconocimiento y mejor disposición del juez para el reconocimiento del derecho nuevo. En su opinión, la postura de nuestro Tribunal Constitucional aparece lastrada por el deseo del constituyente de proclamar todo, estableciendo un catálogo de derechos lo más detallado y puesto al día posible y por su obsesión por dotar de garantías a los derechos con distintos niveles de protección. ${ }^{50}$

Pero, a diferencia de lo que ocurre en otros textos constitucionales (los de EEUU, Portugal, Argentina....), no hay que olvidar que nuestra Constitución no incluye una cláusula abierta de derechos. En cualquier caso, algunos preceptos pueden servir para proporcionar un reconocimiento de nuevos derechos no escritos a pesar de no contener ninguna

47 BVerfGE 32, 373, 379; BVerfGE 103, 21, 32 y ss (Diagnosis del material genético).

48 BVerfGE 65, 1 y ss; 80, 367, 373.

49 Últimamente, BVerfGE 101, 361, 80 (Carolina de Monaco). En este contexto, se están discutiendo las consecuencias de la Sentencia de TEDH de Estrasburgo que desestimó la propia opinión del BVerfG, pidiendo un mayor margen de intimidad para las princesas y sus hijos. 
referencia expresa a dicha lista abierta. Un fundamento posible lo proporciona el art.10.1 CE, a través de su mención a "la dignidad humana, los derechos inviolables que le son inherentes y el libre desarrollo de la personalidad" o por medio de lo preceptuado en el art.10.2 CE. Tal y como ha ocurrido en las sentencias que han sido objeto de estudio, el Tribunal Constitucional se ha hecho eco de la doctrina establecida por el TEDH que sí ha sido muy sensible a este tipo de agresiones acústicas. Ahora bien, según se precisó en su momento, en opinión del Tribunal Constitucional ello no puede suponer una traslación "mimética» de la doctrina europea que ignore las diferencias normativas existentes entre nuestra Norma Suprema y el Convenio Europeo para la Protección de los Derechos Humanos y las Libertades Fundamentales.

Con independencia de la cuestión de los fundamentos jurídico-constitucionales (art.1.1, art.10.1, art 9.2, todos CE) a que hace referencia Díaz Revorio, para entender que nuestra Constitución contiene una «norma general de libertad" o incluso un "derecho general de libertad", resulta necesario analizar con mayor detenimiento la posibilidad de conectar los derechos "no escritos" con otros derechos expresamente recogidos en la Constitución para alcanzar el debido reconocimiento constitucional. Y ello porque ciertamente, el considerarlos reconocidos con base en los arts. 1.1, 10.1 o 9.2 CE supondría la aplicación de los mismos por el Tribunal Constitucional frente al legislador y acaso el reconocimiento por la jurisdicción ordinaria frente a la Administración pública -aunque esto parece más difícil, toda vez que otros interesados en el litigio podrían esgrimir en contra un derecho fundamental reconocido expresamente en la Constitución-, es decir, podrían pasar a ser elementos objetivos del ordenamiento jurídico, pero serían derechos fundamentales débiles - por calificarlos de alguna manera-, pues no estarían protegidos por recurso de amparo ante la jurisdicción ordinaria y el Tribunal Constitucional, habida cuenta de lo dispuesto por los arts. 53.2 CE y 41.1 LOTC ${ }^{51}$. Para que un "derecho nuevo" lo sea en su plenitud, en nuestro sistema, ha de considerarse implícito en alguno de los derechos reconocidos entre los arts 14

51 Artículo 41.1 LOTC: "Los derechos y libertades reconocidos en los artículos 14 a 29 de la Constitución serán susceptibles de amparo constitucional, en los casos y formas que esta Ley establece, sin perjuicio de su tutela general encomendada a los Tribunales de Justicia. Igual protección será aplicable a la objeción de conciencia reconocida en el artículo 30 de la Constitución».

52 Seguimos en este punto a Jiménez de Parga, M., op. Ci, tpágs. 165-167. 


\section{y $30 \mathrm{CE}$.}

Pues bien, en la Constitución española ${ }^{52}$ cabe hablar de algunos derechos no enumerados de forma expresa en el texto constitucional. Es el caso del derecho de rectificación, del principio non bis in idyede la libertad informática.

El derecho de rectificación, no reconocido en el texto fundamental, apareció primero en alguna Sentencia del Tribunal Constitucional (v. gr. STC 35/1983, de 11 de mayo) y luego fue desarrollado por la Ley Orgánica 2/1984, de 26 de marzo.

Por otra parte, ha de recordarse que desde la STC 2/1981, de 30 de enero, nuestro Tribunal Constitucional ha reconocido que el principio non bis in ideintegra el derecho fundamental al principio de legalidad en materia penal y sancionadora (art. 25.1 CE) a pesar de su falta de mención expresa en dicho precepto constitucional, dada su conexión con las garantías de tipicidad y de legalidad de las infracciones. En este sentido el Tribunal ha declarado que este principio veda la imposición de una dualidad de sanciones "en los casos en que se aprecie la identidad de sujeto, hecho y fundamento" (por todas, SSTC 2/1981, de 30 de enero, FJ 4 y 2/2003, de 16 de enero, FJ 3). Recientemente, en la STC 2/2003, de 16 de enero, el Tribunal ha resumido su doctrina al respecto.

53 En su voto particular a la STC 290/2000, de 30 de noviembre, señaló que aunque compartía el fondo de la Sentencia, consideraba que el Tribunal debía haber aludido en ella al reconocimiento y protección de un derecho fundamental, el derecho de libertad informática, que no figura en la tabla de nuestro texto de 1978. Y señalaba los mimbres con los que se podía construir: consideraba esencial el art. 10.1 CE y su reconocimiento de la dignidad de la persona, como eje vertebrador y fuente de consistencia constitucional de ese derecho. Aludía también a otros preceptos constitucionales y a Tratados y Acuerdos Internacionales, así como a Derecho derivado comunitario europeo, como guías de la interpretación constitucional en la cuestión (con base en el art. 10.2 CE).

Como allí recordaba, fue la STC 254/1993, de 20 de julio, la que mencionó, por vez primera en nuestra jurisprudencia, la libertad informática, entendida como un derecho fundamental "en sí mismo". Se trataba de un supuesto en que un ciudadano fundamentó su solicitud de amparo en el art. 18.4 CE, que no reconoce propiamente un derecho fundamental, sino que formula en sentido estricto un mandato al legislador al decir que «la ley limitará el uso de la informática para garantizar el honor y la intimidad personal y familiar de los ciudadanos y el pleno ejercicio de sus derechos".

Lo dicho en aquella primera Sentencia de 1993 se fue aquilatando en otras posteriores. Así, en la relativa a las normas reguladoras del número de identificación fiscal (STC 143/1994, de 9 de mayo). O en las que declararon contrario a la libertad sindical (art. $28 \mathrm{CE}$ ) en relación con el anteriormente citado art. 18.4 de nuestra Carta Magna el 
Y junto al derecho de rectificación y al principio non bis in idem hemos de mencionar otro derecho no reconocido en el texto de la Constitución: el derecho a la libertad informática. Preconizado por el Magistrado Jiménez de Parga ${ }^{53}$, el 30 de noviembre de 2000 nuestro Alto Tribunal aprueba dos importantes Sentencias, núms. 290 y 292/2000 que le conciernen.

La segunda de las Sentencias destacadas ${ }^{54}$, resuelve un recurso de inconstitucionalidad planteado contra ciertos incisos de determinados artículos de la mencionada Ley Orgánica de Protección de Datos de Carácter Personal y contiene una recapitulación y desarrollo del derecho a la libertad informática en nuestra jurisprudencia constitucional. Además, para que el reconocimiento de este derecho fundamental no se quede en el ámbito de la retórica, el Tribunal, en esta Sentencia, aplica vigorosamente el principio de reserva de ley, declarando inconstitucionales determinados incisos de la ley que entregaban determinadas facultades de la Administración pública ${ }^{55}$.

uso por una empresa del dato de la afiliación sindical para detraer haberes de los trabajadores con ocasión de una huelga promovida por un sindicato determinado (entre las que destacan la STC 11/1998, de 13 de enero, que fue la primera, y la STC 94/1998, de 4 de mayo). También en la STC 202/1999, de 8 de noviembre, en la que, con ocasión de la denegación a un trabajador de la cancelación de sus datos médicos en un fichero informatizado de una entidad de crédito sobre bajas por incapacidad temporal, se apreció que el almacenamiento sin cobertura legal en soporte informático de los diagnósticos médicos del trabajador sin mediar su consentimiento expreso constituía una desproporcionada restricción del derecho fundamental a la protección de datos personales.

54 La primera de ellas resuelve varios recursos de inconstitucionalidad sobre determinados preceptos de la Ley Orgánica 5/1992, de 29 de octubre, de Regulación del Tratamiento Automatizado de Datos de Carácter Personal (LORTAD). Cuando se aprobó la Sentencia, la LORTAD ya había sido derogada por la hoy vigente Ley Orgánica 15/1999, de 23 de diciembre, de Protección de Datos de carácter Personal (LOPD). No sorprende, pues, que el fallo declarara la pérdida sobrevenida del objeto de dos de los recursos planteados. Por lo demás, se desestimaron los otros dos recursos de inconstitucionalidad planteados.

55 La Sentencia ha merecido un juicio favorable por parte de la doctrina y es, hasta la fecha, la última que sobre la materia ha aprobado nuestro Tribunal. Con el reconocimiento de este derecho, dice Jiménez de Parga, op. Ioc. .øńtiestro Tribunal ha cumplido una de las tareas más importantes de los Tribunales Constitucionales: extender la tutela a determinadas zonas del Derecho no expresamente consideradas en las correspondientes Constituciones cuando, como ocurre en este caso, es necesario hacerlo para que no queden a la intemperie, sin techo jurídico alguno, intereses esenciales de los ciu- 
Pues bien, al elenco de "derechos nuevos" cabe añadir una especie de derecho al silencio o de derecho a no padecer ruidos evitables, insoportables y prolongados, que se perciban en el domicilio e impidan o dificulten gravemente el libre desarrollo de la personalidad, ni tampoco ruidos que pongan en grave e inmediato peligro la salud de las personas.

Tanto para el TEDH como para el Tribunal Constitucional, el ruido es un agente contaminante del medio ambiente que incide en la intimidad de las personas, y el Tribunal Constitucional ha subrayado que incide en el estado físico y psíquico de las personas. Sin olvidar el paralelismo que existe entre protección del medio ambiente y lucha contra el ruido, la relevancia de la defensa frente a la contaminación acústica radica en los efectos nocivos que produce en el entorno vital de las personas. Como afirma Pérez Martos, posiblemente sea éste uno de los sectores del medio ambiente donde, con mayor facilidad, pueda apreciarse la relación que existe entre este último concepto y la salud humana. En su opinión, "la protección frente al ruido se justifica en la salvaguarda, más que de otros sectores del ambiente, de derechos, bienes, valores y principios ligados al hombre. Algunos relacionados íntimamente con sus posibilidades reales de existencia como su salud, y, otros, no tanto, pero no menos importantes como la dignidad, la intimidad personal y familiar, el desarrollo de su personalidad y la calidad de vida» 56 .

De ahí que la jurisprudencia del TEDH primero y del Tribunal Constitucional después hayan puesto de manifiesto que, aun cuando el ruido es un sector integrante del medio ambiente, en determinadas ocasiones constituye una vulneración del derecho fundamental a la intimidad personal y familiar, en el ámbito domiciliario, a lo que el Tribunal Constitucional ha añadido que el ruido puede afectar al derecho a la integridad física y moral (art. $15 \mathrm{CE}$ ). Ahora bien, es preciso recordar que dicha vulneración se condiciona rigurosamente, dificultando las posibilidades reales para que los Tribunales de Justicia puedan Ilegar a apreciarla. Según lo dicho, en el caso del derecho a la intimidad personal y familiar, se condiciona a que los ruidos sean evitables, insoportables y prolongados, se perciban en el domicilio e impidan o dificulten gravemente el libre desarrollo de la personalidad. En el caso de la integridad física y moral, se supedita a que la exposición continuada a unos niveles intensos de ruido

56 Vid.Pérez Martos, J.: "La protección jurisdiccional frente al ruido (comentario a la Sentencia del Tribunal Constitucional 119/2001, de 24 de mayo), en Revista de Estudios de la Administración Local, no 288 (Enero-Abril 2002), p. 226.

57 STC 16/2004, de 23 de febrero, FJ 3. 
ponga en grave e inmediato peligro la salud de las personas. En ambos casos, se exige que la lesión o menoscabo provenga de una acción u omisión de los poderes públicos ${ }^{57}$.

58 En opinión del Profesor Entrena Ruiz, más bien se debería avanzar «en la atribución a los entes locales de las suficientes herramientas jurídicas y materiales para acotar estos problemas, y en particular para poder sancionar a las personas responsables de ellos, acorde con el principio de autonomía local y su naturaleza eminentemente democrática que tienen reconocidas en la CE, tal y como ha pretendido la Ley 57/2003, de 17 de diciembre, de medidas para la modernización del gobierno local». Vid.Entrena Ruiz, D.: «El ruido, ¿un problema de seguridad pública? La tipificación de infracciones y sanciones mediante ordenanzas locales: abundando en la doctrina constitucional», en Revista Interdisciplinar de Gesti n Ano6 6enjtuio,2004. En este sentido, el autor hace especial mención al Preámbulo de la Ley 57/2003, en virtud del cual, "no podía demorarse por más tiempo la necesidad de colmar la laguna legal que existe en materia de potestad sancionadora municipal en aquellas esferas en las que no encuentren apoyatura en la legislación sectorial, estableciendo criterios de tipificación de las infracciones y las correspondientes escalas de sanciones para que las funciones de esa naturaleza se desarrollen adecuadamente, de acuerdo con las exigencias del principio de legalidad adaptadas a las singularidades locales, y siempre en defensa de la convivencia ciudadana en los asuntos de interés local y de los servicios y el patrimonio municipal, conforme a la doctrina establecida por la Sentencia del Tribunal Constitucional 132/2001, de 8 de junio". Como consecuencia de lo anterior, se ha introducido un nuevo Título en la Ley 7/1985, de 2 de abril, Reguladora de las Bases del Régimen Local (LBRL) que regula la tipificación de infracciones y sanciones por las Entidades locales en determinadas materias. En concreto, el art. 139 de la LBRL contempla la posibilidad de que los entes locales puedan "en defecto de normativa sectorial específica, establecer los tipos de infracción e imponer sanciones por el incumplimiento de deberes, prohibiciones o limitaciones contenidos en las correspondientes ordenanzas con los criterios esta- 


\section{TITUBEOS EN LA POSTURA DEL TRIBUNAL CONSTITUCIONAL ANTE UNA POSIBLE VULNERACIÓN DEL PRINCIPIO DE LEGALI- DAD}

\section{III.1. Excursus acerca del principio de legalidad}

Según se adelantó en su momento, en ocasiones, el Tribunal Constitucional ha mantenido posturas contrapuestas en relación con las sanciones adoptadas por contaminación acústica con graves implicaciones para la seguridad de los perjudicados por este tipo de agresiones. Así, por ejemplo, uno de los problemas que se plantean en las Sentencias 16/2004 y $25 / 2004$ es determinar si la resolución sancionadora municipal impuesta a los demandantes de amparo se ajusta o no a las exigencias que impone el art. 25.1 CE por su dudosa cobertura legal. Esto lleva a plantearnos una relevante cuestión sobre la que volveremos más adelante, esto es, la validez de las posibles soluciones aplicables por los municipios al problema del ruido quizás no debería depender de forma prioritaria de una interpretación del Tribunal Constitucional más o menos amplia sobre las normas que sirven de cobertura $^{58}$. La contradicción en la postura del Tribunal Constitucional que va a ser objeto de estudio acaso tenga su origen en una excesiva laxitud en la interpretación de los límites de la jurisdicción constitucional que podría conllevar una invasión del ámbito que la Constitución reserva al legislador.

Antes de comenzar el análisis sobre la polémica postura del Tribunal Constitucional en las referidas Sentencias, quizás resulte conveniente reflexionar sobre la verdadera justificación que tiene el principio de reserva de ley en la actualidad y recordar someramente la doctrina que ha fijado nuestro Alto Tribunal en materia de legalidad administrativa sancionadora y, en particular, su aplicación a la potestad sancionadora de los entes locales. Asimismo, puesto que en una de las Sentencias se alude a normas preconstitucionales, quizás sea preciso reseñar la influencia que la entrada en vigor de nuestra Constitución de 1978 tuvo en ellas.

blecidos en los artículos siguientes". Asimismo, es necesario hacer referencia al artículo 6 de la Ley 37/2003, de 17 de noviembre, del Ruido, en virtud del cual corresponde a los ayuntamientos aprobar las ordenanzas en relación con las materias objeto de dicha ley. Asimismo, los ayuntamientos deberán adaptar las ordenanzas existentes y el planeamiento urbanístico a las disposiciones de la misma y de sus normas de desarrollo.

59 Vid.Torres del Moral, A.: Principios de Derecho Constitucional Espa ol, Tomo I, $5^{\text {a }}$ edición, Servicio de Publicaciones Facultad de Derecho de la Universidad 
En opinión de Torres del Moral, en nuestra Constitución hay muchas reservas de ley, pero no exactamente una reserva de ley ${ }^{59}$. De los arts. 9.3, 97 y 103.1 CE se desprende que hay una decidida voluntad constitucional de someter a la ley tanto la potestad reglamentaria del Gobierno como cualquier acto de la Administración. Y por otra parte, no le está vedada a la ley ninguna materia. Así pues, se le reservan expresamente las materias más importantes, pero no se le prohíbe ninguna. Por esta razón, Garrorena Morales entiende que hay reservas a procedimientos legislativos especiales. Y Torres del Moral continúa diciendo que acaso sea preferible hablar de primacía y precedencia de ley, esto es, que a la ley le corresponde la normación exclusiva de aquellas materias que le son explícitamente reservadas y la regulación primera de todas las demás. Las reservas de ley que hace la Constitución tienen una doble funcionalidad, pues el legislador queda obligado a regular las materias objeto de las mismas (que, por tanto, son propiamente deberes del legislador, como dice Rubio Llorente), y, además, en ocasiones, debe hacerlo en una determinada dirección, ateniéndose a unos principios que le proporciona el propio texto constitucional. Así pues, el principio de legalidad, añade, vincula positivamente al Poder Ejecutivo y las reservas de ley hacen lo mismo con el Legislativo.

Y es que como ha escrito Rubio Llorente, la finalidad de la reserva de ley no es en nuestra Constitución la de sustraer ciertas materias a la potestad reglamentaria, porque el ejercicio de ésta requiere siempre un apoderamiento legal; con la reserva se trata de imponer al legislador el deber de

60 Vid. Rubio Llorente, F.: "El principio de legalidad", en Revista Espa ola de Derecho Constituciondúm. $37-39$ (1993), págs. 24 y ss.; Garrorena Morales, A.: El lugar de la ley en la Constituci n espaCen̈tro de Estudios Constitucionales, Madrid, 1980, págs. 78-92 y 103.

61 Vid.De Otto, l.: Derecho Constitucional. Sistema de fuAriedsBarcelona, 1987, págs. 153 y ss. En términos similares, vid.Torres Del Moral, A.: Principios de Derecho Constitucional Espa ala edición, Servicio de Publicaciones Facultad de Derecho de la Universidad Complutense, Madrid, 1998, págs. 160 y ss; Aragón Reyes, M.: "La función legislativa de los parlamentos y sus problemas actuales», en EI parła mento $y$ sus transformaciones actuales: Jornadas organizadas por la Asamblea Regional de Murcid,Garronera Morales (ed.), Tecnos, Madrid, 1990, p. 136. Villacorta Mancebo, L.: Reserva de ley y ConstituDżkinson, Madrid, 1994, p. 69; López Pina, A.: "Tareas del Estado y lugar de la Ley", en Jornadas de Derecho Constitucional Comparado. Democracia representativa y parlamentarismo: Alemania, Espa a, Gran Breta a e ItaliA., López Pina (dir.), Secretaría General del Senado, Servicio de Publicaciones, Madrid, 1994, págs. 36-37. Ahora bien, el poder legislativo no es legítimo porque se ejerza de acuerdo con un determinado procedimiento; se adecua a ese pro- 
regular por sí mismo determinadas materias ${ }^{60}$. De ahí que la verdadera justificación del principio de reserva de ley esté, precisamente, en poder asegurar que la regulación de una serie de materias (como ocurre con el régimen sancionador) se efectúe por el Parlamento nacional con el fin de garantizar que su adopción venga acompañada de un debate, en el que concurran los distintos representantes de la sociedad, a través de las mayorías pero también de las minorías parlamentarias. Al someter estas materias a la discusión pública parlamentaria, la reserva de ley presta a la normativa resultante un plus de legitimidad, dice De Otto, y garantiza para ella el pluralismo democrático, al dar a la oposición la posibilidad de exponer sus puntos de vista y movilizar a la opinión pública en un procedimiento legislativo que se asienta sobre la publicidad, la contradicción y el debate. 61

Sobre este extremo, resulta interesante aludir a la Sentencia 83/1984, de 24 de julio, del Tribunal Constitucional, como expresión de una consolidada doctrina: "El principio de reserva de Ley entraña una garantía esencial de nuestro Estado de Derecho, y como tal ha de ser preservado. Su significado último es el de asegurar que la regulación de los ámbitos de libertad que corresponden a los ciudadanos dependa exclusivamente de la voluntad de sus representantes, por lo que tales ámbitos han de quedar exentos de la acción del ejecutivo $y$, en consecuencia, de sus productos normativos propios, que son los reglamentos. El principio no excluye, ciertamente, la posibilidad de que las leyes contengan remisiones a normas reglamentarias, pero sí que tales remisiones hagan posible una regulación independiente y no claramente subordinada a la Ley, lo que supondría una degradación de la reserva formulada por la Constitución en favor del legislador. Esto se traduce en ciertas exigencias en cuanto al alcance de las

62 Vid.De Otto, l, op. ci tpágs. 153 y ss.

63 Vid.STC 18/1981, de 8 de junio, así como el comentario a esta sentencia de García De Enterría, E.: "La incidencia de la Constitución sobre la potestad sancionadora de la Administración: dos importantes sentencias del Tribunal Constitucional», en REDA núm. 29 (1981), págs. 359 y 362 y ss. (En dicho artículo, García de Enterría comenta asimismo la Sentencia del Tribunal Constitucional de 30 de enero de 1981 que, partiendo del artículo 25.1 de la Constitución, argumentó la exigencia de que una determinada acción u omisión estuviera incluida en un tipo penal o en un tipo de infracción administrativa, nunca simultáneamente en ambos, y que esa inclusión, en todo caso, fuera obra de la Ley).

64 Para una descripción más pormenorizada del principio de reserva de ley, con motivo del análisis de las SSTC 5/2003 y 52/2003, vid.Serrano-Suñer, G. y González Botija, F.: Comentarios a la Ley de la Vi a y del Vino. Ley 24/2003, de 10 de julio, 
remisiones o habilitaciones legales a la potestad reglamentaria, que pueden resumirse en el criterio de que las mismas sean tales que restrinjan efectivamente el ejercicio de esa potestad a un complemento de la regulación legal que sea imprescindible por motivos técnicos o para optimizar el cumplimiento de las finalidades propuestas por la Constitución o por la propia Ley." En definitiva, el principio general es que en las materias sujetas a reserva de ley es posible la remisión al reglamento, en tanto en cuanto esto no suponga una alteración de la reserva misma establecida en favor del legislador ${ }^{62}$.

Centrando ahora la atención en el régimen sancionador de las infracciones administrativas, el Tribunal Constitucional ya en una de sus primeras sentencias, señaló "que los principios inspiradores del orden penal son de aplicación, con ciertos matices, al Derecho administrativo sancionador, dado que ambos son manifestaciones del ordenamiento punitivo del Estado, tal y como refleja la propia Constitución "63. De acuerdo con esta consolidada doctrina constitucional, recogida de forma exhaustiva en las recientes SSTC 50/2003 y 52/2003, ambas de 17 de marzo, el término "legislación vigente" contenido en el artículo 25.1 de la Constitución de 1978 es expresivo de una reserva de ley en materia sancionadora ${ }^{64}$. No obstante, afirma, en el contexto de las infracciones y sanciones administrativas, el alcance de la reserva de ley establecida en el art 25.1 no puede ser tan riguroso como lo es por referencia a los tipos y sanciones penales en sentido estricto; $y$ ello "tanto por razones que atañen al modelo constitucional de distribución de las potestades públicas como por el carácter en cierto modo insuprimible de la potestad reglamentaria en determinadas materias, o bien, por último, por exigencias de prudencia o de oportunidad». En todo caso, advierte el Tribunal Constitucional, aquel precepto constitucional determina la necesaria cobertura de la potestad sancionadora de la Administración en una norma de rango legal, habida cuenta del carácter excepcional que presentan los poderes sancionadores en manos de la Administración ${ }^{65}$. En concreto, el núcleo central de la materia sancionadora reservado constitucionalmente al legislador es como regla general, el relativo a la predeterminación de las infracciones, de las sanciones y de la correspondencia entre ambas ${ }^{66}$.

En este punto, las dos Sentencias que van a ser objeto de estudio (SSTC 16/2004 y 25/2004) destacan cómo la STC 132/2001, de 8 de junio,

65 STC 3/1981, de 21 de enero (FJ 9) y STC 305/1993, de 25 de octubre (FJ 3).

66 STC 16/2004, de 23 de febrero (FJ 3). 
matiza la referida esfera material básica reservada al poder legislativo en el ámbito sancionador cuando se está en presencia de normas reglamentarias aprobadas por el Pleno del Ayuntamiento al existir, de conformidad con el interés local, un amplio campo para este tipo de regulación local siempre que se esté dentro de su campo competencial. En cualquier caso, dicha flexibilización no permite la existencia de reglamentos municipales independientes pues la mera atribución por ley de competencias a los Municipios - conforme a la exigencia del art. 25.2 LBRL- no contiene en sí la autorización para que cada Municipio tipifique por completo y según su propio criterio las infracciones y sanciones administrativas en los ámbitos de su competencias. En este sentido, el Tribunal Constitucional especifica las dos exigencias mínimas que se derivan del art. 25.1 CE: "en primer término, y por lo que se refiere a la tipificación de infracciones, corresponde a la ley la fijación de los criterios mínimos de antijuridicidad conforme a los cuales cada Ayuntamiento puede establecer tipos de infracciones; no se trata de la definición de tipos — ni siquiera de la fijación de tipos genéricos de infracciones luego completables por medio de Ordenanza Municipal- sino de criterios que orienten y condicionen la valoración de cada Municipio a la hora reestablecer los tipos de infracción. En segundo lugar, y por lo que se refiere a las sanciones, del art.25.1 CE deriva la exigencia, al menos, de que la ley reguladora de cada materia establezca las clases de sanciones que pueden establecer las ordenanzas municipales; tampoco se exige aquí que la ley establezca una clase específica de sanción para cada grupo de ilícitos, sino una relación de las posibles sanciones que cada Ordenanza Municipal puede predeterminar en función de la gravedad de los ilícitos administrativos que ella misma tipifica» ${ }^{67}$.

En relación con el Derecho preconstitucional, el Tribunal Constitucional vuelve a insistir en que no es posible exigir la reserva de ley de manera retroactiva para anular o considerar nulas disposiciones reglamentarias reguladoras de materias y situaciones respecto de las cuales tal reserva no existía. En este sentido, el Tribunal Constitucional ha llegado a considerar acorde con la Constitución el supuesto en que la norma reglamentaria post-constitucional se limite, sin innovarel sistema de infracciones y sanciones en vigor, a aplicar ese sistema preestablecido al objeto de particularizarlo de su propia regulación material ${ }^{68}$. En otras

67 STC 132/2001, de 8 de junio (FJ 6).

68 STC 42/1987, de 7 de abril (FJ 4).

69 SSTC 305/1993, de 25 de octubre (FJ 6), 45/1994, de 15 de febrero (FJ 5) y 52/2003, de 17 de marzo (FJ 10). 
palabras, a partir de la Constitución, no es lícito tipificar ni introducir nuevas sanciones o alterar el cuadro de las existentes mediante una norma reglamentaria cuyo contenido no esté suficientemente predeterminado o delimitado por otra norma de rango legal, puesto que ello no respetaría el sistema de producción de normas jurídicas impuestas por nuestra Carta Magna. En esta misma línea, el Tribunal Constitucional subraya la importancia de las SSTC 305/1993, 45/1994, 117/1995 y más recientemente la STC 52/2003, de 17 de marzo, que avanzaron en la advertencia de que «la lógica coherencia y continuidad normativa con la regulación preconstitucional no puede suponer - sobre la base de que se reiteran disposiciones reglamentarias preconstitucionales sancionadoras ya existentes-que la Administración ostente potestades sancionadoras no amparadas por una cobertura suficiente de normas con rango legal; pues ello representaría convertir en buena medida en inoperante el principio de legalidad de la actividad sancionadora de la Administración con sólo reproducir, a través del tiempo, las normas reglamentarias sancionadoras preconstitucionales, manteniéndose así in aeternumdespués de la Constitución, sanciones sin cobertura legal» ${ }^{69}$.

\section{III.2. Divergencias entre las SSTC 16/2004, de 23 de febrero y 25/2004, de 26 de febrero}

\section{III.2.A. STC 16/2004, de 23 de febrero}

Delimitados los anteriores aspectos de obligada referencia para poder entrar en el examen sobre la controvertida postura adoptada por el Tribunal Constitucional en torno a una posible vulneración del principio de

70 De conformidad con el a.1.2 de la Ley, "se entiende por contaminación atmosférica, a los efectos de esta Ley, la presencia en el aire de materias o formas de energía que impliquen riesgo, daño o molestia grave para las personas y bienes de cualquier naturaleza».

${ }^{71}$ La Ley 38/1972, en su art. 12 dice: "Las infracciones a lo dispuesto en esta Ley y en las disposiciones que la desarrollen serán sancionadas conforme se expresa en los apartados siguientes, sin perjuicio, en su caso, de las correspondientes responsabilidades civiles y penales: a) Con multa de hasta 5.000 pesetas, tratándose de vehículos de motor; de hasta 25.000 pesetas en relación con los generadores de calor, y de hasta 500.000 pesetas cuando se trate de los demás focos emisores de contaminantes a la atmósfera o de suministro de combustibles y de carburantes que no se ajusten a lo establecido en el artículo $4^{\circ}$ de esta Ley. El artículo 13.1 atribuye a los alcaldes competencia para imponer sanciones cuando la cuantía no exceda de 100.000 pesetas. 
legalidad en materia sancionadora, en su vertiente relativa al principio de reserva de ley, se hará mención en primer lugar a la STC 16/2004, de 23 de febrero, que fue aprobada gracias al voto de calidad del entonces Presidente D. Manuel Jiménez de Parga.

En el recurso de amparo promovido por el titular del establecimiento «Pub Belfast», sancionado por infracción grave tipificada en el art 28 de la Ordenanza Municipal sobre protección contra la contaminación acústica del Ayuntamiento de Gijón, el Tribunal encontró suficiente cobertura legal en la Ley 38/1972, de 22 de diciembre, de Protección del Ambiente Atmosférico. A su juicio, la referida Ley establecía unos criterios mínimos orientativos conforme a los cuales el Ayuntamiento pudo establecer el correspondiente cuadro de infracciones. En concreto, el carácter genérico de las previsiones de la Ley, tanto en lo que se refiere al concepto de contaminación ${ }^{70}$, como a las infracciones ${ }^{71}$ dejaba afirmar que la infracción tipificada era una concreción de la misma. Para justificar que, a pesar de estar ante una concreción de un supuesto de contaminación no previsto expresamente en la Ley, el carácter genérico de algunos de sus términos permitía incluirlo sin considerar que se había producido una mutación sustancial del concepto básico, el Tribunal tuvo en cuenta los siguientes extremos: que el ruido puede ser calificado como "partículas o formas contaminantes" o incluso como "forma de energía" que se emite a la atmósfera e implica "riesgo, daño o molestia grave para las personas y bienes de cualquier naturaleza" de acuerdo con el art. 1.2 de la Ley 38/1972 que habla constantemente de "focos de emisión". En definitiva, el Tribunal Constitucional consideró que "cualquiera que fuese la voluntad del Legislador de 197el"ruido podía encajar en algunas de las expresiones citadas, no tanto como "partículas" sino más bien como "formas" en general. Y en este sentido, concluía que «el ruido en cuanto provoca determinadas ondas que se expanden en el aire, puede incluirse en esta expresión, "formas de energía", y tal posición es asumida por la Ordenanza municipal» ${ }^{72}$. De ahí, que se desestimara el amparo solicitado.

Sin embargo, tres de los seis Magistrados de la Sala Primera del Tribunal Constitucional formularon un voto particular discrepante que fundamentaron precisamente en la amplitud de la interpretación realizada de contaminación atmosférica: "el ruido no puede ser calificado como «materias o formas de energía" por mas que sus ondas se expandan en el aire». Para justificar que la Ley de Protección del Ambiente Atmosférico de 1972

72 Vid.STC 16/2004 (FJ 4). 
no podía servir de cobertura legal a la resolución sancionadora impuesta por los excesos de ruido, los Magistrados se remitieron precisamente al Preámbulo de la Ley preconstitucional que reconocía, ante "la dificultad primaria de los programas de defensa del medio ambiente", dada "su extrema complejidad", su limitación a la regulación de aspectos parciales. Y en tal sentido, destacaban cómo la Ley citaba en concreto "la lucha contra el ruido" entre "tantos otros...aspectos parciales de una política general de múltiples facetas, en buena parte inexploradas, y cuya comprensión y ordenación global exige unos instrumentos legales de los que hoy no se dispone. En esta línea no cabe duda de que el criterio óptimo de actuación sería preparar una Ley general para la defensa del medio ambiente, en la que se considerasen armónicamente todos los problemas apuntados. Sin embargo, la presión de las circunstancias obliga a aplazar momentáneamente la antedicha solución legislativa». Estas circunstancias obligaron al Gobierno a adoptar "una actitud pragmática e iniciar sus programas de actuación con regulaciones sectoriales, comenzando por el tema, ya grave en muchas de nuestras aglomeraciones urbanas, de la contaminación del aire».

Los Magistrados discrepantes basan su argumentación en la reciente Ley 37/2003, de 17 de noviembre, del Ruido, "de la que la Sentencia predica en su fundamento jurídico 2 su sensibilidad ante la "nueva realidad", transcribiendo la parte primera de su Exposición de Motivos, que declara que "el ruido en su vertiente ambiental, no circunscrita a ámbitos específicos como el laboral, sino en tanto que inmisión sonora presente en el hábitat humano o en la naturaleza, no ha sido tradicionalmente objeto de atención preferente en la normativa protectora del medio ambiente" y especifica que "el ruido carecía hasta esta ley de una norma general reguladora de ámbito estatal, y su tratamiento normativo se desdobla, a grandes rasgos, entre las previsiones de la normativa civil en cuanto a relaciones de vecindad y causación de perjuicios, la normativa sobre limitación del ruido en el ambiente de trabajo, las disposiciones técnicas para la homologación de productos y las ordenanzas municipales que conciernen al bienestar ciudadano o al planeamiento urbanístico".

\section{III.2.B. STC 25/2004, de 26 de febrero}

Tres días después de la aprobación por parte de la Sala Primera de la STC 16/2004, de 23 de febrero, la Sala Segunda del Tribunal Constitucional, en la STC 25/2004, de 26 de febrero, reconoció en un supuesto muy similar, la vulneración del principio de legalidad en materia sancionadora por enten- 
der que la infracción prevista en el art. $28.2 \mathrm{~g}$ ) de la Ordenanza de Medio Ambiente contra las perturbaciones por ruidos y vibraciones del Ayuntamiento de Santander, que calificaba como infracción grave el ejercicio de actividades industriales con puertas o ventanas abiertas no tenía cobertura legal suficiente en la LO 1/1992, de 21 de febrero, sobre protección de la seguridad ciudadana (LOPSC). En concreto, en su art. 23 ñ) que tipificaba como infracción administrativa grave "la apertura de un establecimiento, el inicio de su actividad o el desarrollo de su funcionamiento sin adoptar total o parcialmente las medidas de seguridad obligatorias o cuando aquéllas no funcionen o lo hagan defectuosamente, o antes de que la autoridad competente haya expresado su conformidad con las mismas". El otro posible precepto de la LOPSC que, en opinión del Ministerio Fiscal, podía justificar la necesaria cobertura legal era el artículo $23 \mathrm{~d}$ ) -actual 23 e) tras la reforma introducida por la LO 4/1997-que tipifica como infracción grave «la apertura de establecimientos y la celebración de espectáculos públicos y actividades recreativas careciendo de autorización o excediendo de los límites de la misma». Aparte de ello, el Ministerio Fiscal entendía que, en la medida en que la LO 1/1992 pretende, entre otros aspectos, proteger el libre ejercicio de los derechos y libertades, entre los que se encuentra el derecho a la intimidad, y que las potestades administrativas contempladas en ella tienen como finalidad asegurar la convivencia humana, también desde una perspectiva material las infracciones y sanciones previstas permiten afirmar la cobertura legal de la Ordenanza municipal de Medio Ambiente. En su opinión, la calificación de "medio ambiente» no significa que necesariamente el reglamento municipal haya de basarse en una ley concreta, cuando la actividad infractora puede considerarse como pluriofensiva y cuando puede afirmarse que los reglamentos municipales no constituyen supuestos de desarrollo directo de leyes determinadas, sino el ejercicio de la potestad normativa de los entes locales.

Para negar la cobertura legal de la sanción impuesta por el Ayuntamiento de Santander, el Tribunal parte de la idea restrictiva de "seguridad pública" presente en la doctrina constitucional, en virtud de la cual dicho concepto "se refiere a la protección de personas y bienes y al mantenimiento de la tranquilidad u orden ciudadano". Ahora bien, no toda seguridad de personas y bienes, ni toda normativa encaminada a conseguirla o a preservar su mantenimiento, puede englobarse en aquélla, pues, si así fuera, la práctica totalidad de las normas del Ordenamiento serían normas de seguridad pública. En esta misma línea de precisión, el Tribunal

73 STC 119/2001 (FJ 5). 
Constitucional advierte que su ámbito de aplicación se debe caracterizar por referirse a situaciones o productos que son susceptibles de ocasionar graves riesgos para personas y bienes que exijan la adopción de medidas de especial intensidad. A la vista de esta idea restrictiva del concepto de "seguridad pública», el Tribunal Constitucional entiende que el art. 23 ñ) de la LO 1/1992 no puede constituir una cobertura legal suficiente para la sanción impuesta al demandante de amparo con el cierre de la discoteca "Indian» por el período de un mes, por infracción de la Ordenanza municipal sobre protección del medio ambiente contra la emisión de ruidos y vibraciones.

Sin embargo, en este punto, no hay que olvidar las graves consecuencias que el ruido puede tener sobre la salud de la personas y la conducta social que el Tribunal Constitucional quiso destacar en la Sentencia 119/2001, de 24 de mayo, con motivo del recurso de amparo interpuesto por una señora que vivía en una zona de bares y discotecas. Según se explicó en su momento, aunque el fallo fue denegatorio entre otros motivos por la debilidad del material probatorio-, el Tribunal Constitucional admitió que el ruido "puede llegar a representar un factor psicopatógeno destacado en nuestra sociedad y una fuente permanente de perturbación de la calidad de vida de los ciudadanos ${ }^{73}$. Para ello, se apoyaba en las directrices marcadas por la Organización Mundial de la Salud sobre el ruido ambiental que ponen de manifiesto las consecuencias de una exposición prolongada a un nivel elevado de ruido, tanto sobre la salud de la personas como sobre la conducta social. Las graves consecuencias de los excesos de ruido derivados de este tipo de locales tan comunes en las "movidas nocturnas" fueron asimismo puestas de relieve en la STC $16 / 2004$, de 23 de febrero, que como es sabido encuadra el ruido en el marco de los derechos fundamentales. En lo que ahora interesa, ha de recordarse que el Tribunal Constitucional admite que si la exposición continuada a unos niveles intensos de ruido pone en grave peligro la salud de las persestassituación podría implicar una vulneración del derecho a la integridad física y moral. Asimismo, de conformidad con dicha Sentencia, una exposición prolongada a determinados niveles de ruido, que puedan objetivamente calificarse de evitables e insoportables, ha de merecer la protección dispensada al derecho fundamental a la intimidad personal y familiar, en el ámbito domiciliario.

Volviendo al concepto de "seguridad pública" que el Tribunal Constitucional delimita en términos tan restrictivos en la STC 25/2004, conviene destacar otro argumento un tanto cuestionable. En su opinión, la eliminación o disminución de los ruidos y las vibraciones de las fuentes productoras en las distintas instalaciones y actividades sujetas a la 
misma, se encuentra encaminada a procurar una mayor tranquilidad a los vecinos $y$, en este sentido, puede considerarse relacionada con la seguridad pública. Sin embargo, advierte, "la Ordenanza no deja de establecer un conjunto de reglas que protege la tranquilidad ciudadana a través de una intervención administrativa que no resulta extraordinaria y que se desarrolla de manera constante y regul,apermitiendo el funcionamiento normal de las actividades afectadas de modo que los ruidos y vibraciones que produzcan no alteren la calidad de vida de los ciudadanos". Es el caso, pone como ejemplo, de "la policía de espectáculos" que se caracteriza por el hecho de que sus medidas o disposiciones permiten el desarrollo ordenado del acontecimiento, según la naturaleza del espectáculo de que se trate, sin necesidad de acudir a medidas extraordinarias. En definitiva, son medidas que, velando por el buen orden de los espectáculos, se dirigen a la protección de las personas y bienes "a través de una intervención administrativa ordinaria -de carácter normal y constante- (STC 313/1994, de 24 de noviembre)". Desgraciadamente, la mayoría de las demandas de tutela frente al ruido provienen de ciudadanos que se quejan de la inactividad de la Administración o bien, como critica Marín Castán, "perdida toda esperanza de que ésta cumpla eficazmente sus obligaciones, buscan vías judiciales alternativas procediendo directamente contra el causante del ruidon 74 .

Por último, en relación con el otro posible precepto con el que el Ministerio Fiscal trataba de justificar la necesaria cobertura legal, el Tribunal Constitucional Ilega a la misma conclusión: se ha de excluir la cobertura del art. 23 d) de la LO 1/1992 pues es evidente que la expresión "excediendo de los límites de la autorización» debe entenderse referida a límites que guarden consonancia con el preciso objeto de la Ley Orgánica sobre protección de la seguridad ciudadana. Por otra parte, advierte que la Administración actuante "en ningún momento ha afirmado que la conducta de la demandante de amparo objeto de reproche supusiera un exceso respecto de los límites de la autorización concedida en su día ${ }^{75}$. En definitiva, según el Tribunal Constitucional, el diferente ámbito en el que se mueven la LO 1/1992 y la Ordenanza municipal impide que, sin desvirtuar el concepto de seguridad pública, pueda emplearse cualquiera de los tipos de infracción establecidos en el art. 23 de la reiterada LO 1/1992 para otorgar la oportuna cobertura legal a la infracción impuesta por la emisión de

74 Vid.Marín Castán, F., op. cit p, 120.

75 STC 25/2004 (FJ 8). 
ruidos.

De las sentencias comentadas es fácil concluir que la doctrina constitucional ha seguido interpretaciones muy distintas en relación con la tipificación de infracciones y sanciones adoptadas por los Ayuntamientos contra el exceso de ruido, con decisivas repercusiones sobre los perjudicados. A su vez, es preciso subrayar las graves implicaciones que dichas interpretaciones contrapuestas tienen sobre la seguridad jurídica, principio esencial de nuestro ordenamiento jurídico que nuestra Constitución proclama y garantiza en el art. 9.3 con eficacia jurídica cierta. En efecto, a la hora de solucionar futuros problemas relacionados con el Medio Ambiente y en particular con el descanso de los ciudadanos, nuestro Alto Tribunal puede interpretar la ley de cobertura en sentido amplio, justificando la imposición de sanciones administrativas por contravenir la normativa municipal sobre contaminación acústica o, por el contrario, de forma más estricta como sucede en la STC 25/2004. Con esta forma de actuar, se hace un flaco favor a la certeza sobre el ordenamiento jurídico aplicable y sobre los intereses jurídicamente tutelados que la Constitución exige a todos los poderes públicos. En concreto, la Constitución encomienda al Tribunal Constitucional la protección última de los derechos y libertades de los ciudadanos, fiscalizando incluso a los órganos judiciales. No debe olvidarse que, como advierte Torres del Moral, junta a esta protección, debe resaltarse la muy importante función de "unificación de la jurisprudencia de los órganos judiciales en materia tan relevante y delicada como los derechos y libertades, lo cual afianza igualmente la seguridad jurídica». ${ }^{76}$

\section{III.2.C. Consideraciones finales sobre la controvertida postura del Tribunal Constitucional ante una posi- ble vulneración del principio de legalidad}

Mantener que el ruido es un atentado contra determinados derechos fundamentales —con la consiguiente obligación constitucional dirigida a todos los poderes públicos para que contribuyan a la efectividad de los mismos - no puede obviar otros derechos fundamentales cuyo ejercicio real y efectivo está igualmente previsto en nuestra Constitución.

Si nos preguntamos qué doctrina contiene la STC 16/2004, hemos de

76 Vid.Torres del Moral, A.: Estado de Derecho y democracia de part2a ción, Servicio de Publicaciones de la Facultad de Derecho de la Universidad Complutense de Madrid, Madrid, 2004, p. 205. 
concluir que lo que dice es algo así como que el ruido es tan grave que la represión del mismo está sometida a un principio de legalidad debilitado. En efecto, los fundamentos jurídicos utilizados para justificar la incidencia que el ruido tiene sobre la integridad real y efectiva de los derechos fundamentales parecen ser una suma de obiter dicque no deberían conducir al fallo que adoptó la mayoría. Sin embargo, en la medida en que constituyen la explicación del debilitamiento de las exigencias derivadas del principio de legalidad en materia sancionatoria, se convierten en ratio decidendiResulta discutible la aplicaci de la doctrina sobre el principio de reserva de ley en materia sancionadora al caso enjuiciado, así como de la influencia que tuvieron en el fallo las consideraciones a propósito de los derechos a la integridad física y moral, a la intimidad personal y familiar y a la inviolabilidad del domicilio no alegados por las partes que, para los Magistrados firmantes del voto particular, no venían al caso y sin embargo la Sentencia considera "derechos fundamentales implicados".

Creemos estar ante un caso límite de las posibilidades de expansión de las competencias del Tribunal Constitucional. La fuerza del Tribunal Constitucional, que no ostenta la representación popular, órgano constitucional de legitimación nomocrática y sólo muy indirectamente democrática, es la del Derecho y sus decisiones deben fundarse en un razonamiento que respete rigurosamente los requisitos propios de la interpretación jurídica. Nuestro máximo intérprete de la Constitución, advierte Rubio Llorente (aunque no a propósito de esta Sentencia), no puede abstraer de los preceptos constitucionales el valor o los valores que, a su juicio, tales preceptos encarnan, para deducir después de ellos graves consecuencias

77 Entre otros muchos, Rubio Llorente ha sido muy crítico a este tipo de vulneraciones del principio de separación de poderes inherente a la idea de Estado de Derecho. En su opinión, esto no es ni siquiera hacer jurisprudencia de valores, sino lisa y llanamente suplantar al legislador o, quizá más aún, al propio poder constituyente. Los valores que inspiran un precepto concreto pueden servir, en el mejor de los casos, para la interpretación de ese precepto, no para deducir a partir de ellos obligaciones (nada menos que del poder legislativo, representación del pueblo!) que el precepto en modo alguno impone. En definitiva, la proyección normativa de los valores constitucionalmente consagrados corresponde al legislador, no al Juez. En este sentido, ver su voto particular a la polémica STC 53/1985, de 11 de abril (BOE 119/1985, de 18 de mayo de 1985).

78 Se escriben estas líneas el 18 de diciembre de 2004.

79 A su vez, hay que tener en cuenta que la composición de las Salas cambió por Acuerdo de 16 de junio de de 2004 (BOE de 24 de junio). En la Sala Primera, hay dos Magistrados firmantes del voto particular de la STC 16/2004, dos favorables al criterio de la mayoría que aprobó la STC mencionada y dos que no se han pronunciado. En la Sala Segunda hay cuatro Magistrados que aprobaron la STC 25/2004. 
jurídicas que no tienen apoyo en ningún texto constitucional concreto ${ }^{77}$.

En cuanto a qué doctrina pueda prevalecer en el futuro, tan solo cabe hacer especulaciones que tengan en cuenta el sentido del voto de los Magistrados en resoluciones pasadas, si bien debe subrayarse que son infinitos los matices por los que el parecer de cada miembro de un órgano jurisdiccional colegiado puede evolucionar. En todo caso, merece la pena tener presente que la composición del Tribunal Constitucional cambió por RD de 8 de junio de 2004 (BOE de 9 de junio). En la actualidad, ${ }^{78}$ en el Pleno hay cuatro Magistrados que en su día aprobaron la STC 25/2004, más dos Magistrados que firmaron el voto particular a la STC 16/2004, cuatro Magistrados que no se han pronunciado sobre la cuestión, y sólo dos que se pronunciaron a favor de la STC $16 / 2004^{79}$.

\section{FUNCIÓN IMPULSORA DEL TRIBUNAL CONSTITUCIONAL $Y$ DEL TRIBUNAL EUROPEO DE DERECHOS HUMANOS}

Como contrapunto a la crítica realizada a la errónea concepción de la jurisdicción constitucional, antes de terminar el presente trabajo, quisiéramos destacar la muy eficaz función impulsora o promotora del Tribunal Constitucional y del TEDH para abordar una materia cuya regulación manifiestamente incompleta ha contribuido a deteriorar de forma alarmante la protección contra la contaminación acústica. En este sentido, resulta obligado alabar las puertas que ha abierto la jurisprudencia, al sugerir decisivas mejoras y eliminar importantes vacíos en la regulación comunitaria y nacional del ruido.

\section{Derecho comunitario}

Durante muchos años, la Unión Europea había dado una escasa prioridad al ruido en parte debido al hecho de que, según hemos podido comprobar, se trata de un problema local que adopta formas muy variadas en diferentes partes de la Unión en cuanto a la aceptación del problema. Sin embargo, ante el elevado y creciente número de agresiones acústicas, a partir del Libro Verde sobre "Política Futura de Lucha Contra el Ruido" se tomó conciencia de la necesidad de aclarar y homogeneizar el entorno normativo del ruido por ser uno de los mayores problemas medioambientales en Europa. Como consecuencia de este reconocimiento, se aprobó la Directiva 2002/49/CE del Parlamento Europeo y el Consejo, de 25 de junio

80 DOCE L 189/12, de 18-7-2002. 
de 2002 , sobre evaluación y gestión del ruido ambiental ${ }^{80}$. Con ella se pretende proporcionar una base para desarrollar y completar el conjunto de medidas comunitarias existentes sobre el ruido emitido por las principales fuentes, en particular vehículos e infraestructura de ferrocarril y carretera, aeronaves, equipamiento industrial y de uso al aire libre y máquinas móviles.

Entre las categorías de emisiones de ruidos procedentes de determinados productos que ya estaban cubiertas por la legislación comunitaria, cabe destacar, la Directiva 70/157/CEE del Consejo, de 6 de febrero de 1970, relativa a la aproximación de las legislaciones de los Estados miembros sobre el nivel sonoro admisible y el dispositivo de escape de los vehículos a motor, la Directiva 77/311/CEE del Consejo, de 29 de marzo de 1977, relativa a la aproximación de las legislaciones de los Estados miembros sobre el nivel sonoro en los oídos de los conductores de tractores agrícolas o forestales de ruedas, la Directiva 80/51/CEE del Consejo, de 20 de diciembre de 1979, relativa a la limitación de las emisiones sonoras de las aeronaves subsónicas y las Directivas que la completan, esto es, la Directiva 92/61/CEE del Consejo, de 30 de junio de 1992, relativa a la recepción de los vehículos de motor de dos o tres ruedas y la Directiva 2000/14/CE del Parlamento Europeo y del Consejo, de 8 de mayo de 2000, relativa a la aproximación de las legislaciones de los Estados miembros sobre emisiones sonoras en el entorno debidas a las máquinas de uso al aire libre. Por último, en relación con la protección contra las agresiones sonoras en los aeropuertos, hay que mencionar asimismo la Directiva 2002/30/CE, del Parlamento Europeo y del Consejo, de 26 de marzo de 2002, sobre el establecimiento de normas y procedimientos para la introducción de restricciones operativas relacionadas con el ruido en los aeropuertos comunitarios ${ }^{81}$.

\section{Derecho espa ol}

Según se explicó en su momento, la primera idea sobre la que insiste la nueva Ley 37/2003, de 17 de noviembre, es que «el ruido carecía hasta esta ley de una norma general reguladora de ámbito estatal, y su tratamiento normativo se desdoblaba, a grandes rasgos, entre las previsiones de la normativa civil en cuanto a relaciones de vecindad y causación de perjuicios, la nor-

81 DOCE L 85/40, de 28-3-2002.

82 Sobre los factores que propiciaron el nacimiento de la Ley 37/2003, ver González Pastor, C.: "La nueva Ley del Ruido: regulación administrativa y regulación penal como delito contra el medio ambiente. Comentario a la Sentencia del Tribunal Constitucional 
mativa sobre limitación del ruido en el ambiente de trabajo, las disposiciones técnicas para la homologación de productos y las ordenanzas municipales que conciernen al bienestar ciudadano o al planeamiento urbanístico". En efecto, la nueva Ley del Ruido -más amplia que la Directiva 2002/49 del Parlamento Europeo y del Consejo de 25 de junio, sobre evaluación y gestión del ruido ambiental que incorpora- da la oportuna respuesta legal a una creciente demanda social frente a la invasión acústica. ${ }^{82}$

Lejos de incluir un análisis exhaustivo sobre su contenido, cabo destacar varios puntos incluidos en la nueva Ley que afectan a algunos de los problemas suscitados en las sentencias del Tribunal Constitucional que han sido objeto de estudio. En el Capítulo I, la Ley del Ruido incluye una disposición sobre la distribución competencial en materia de contaminación acústica que prevé expresamente la competencia de los Ayuntamientos para la aprobación de las Ordenanzas sobre el ruido y para la adaptación de las ya existentes a las previsiones de la nueva Ley. Todo ello, sin perjuicio de la competencia de las CCAA en relación con la gestión en materia de protección de medio ambiente prevista en la mencionada disposición, en consonancia con el art. 148.1.9 CE. A su vez, el Capítulo IV contempla el tan esperado sistema de inspección y régimen sancionador.

Por último, es preciso insistir en que para conseguir esta reciente normativa global y exhaustiva frente al ruido también ha sido fundamental la actuación de determinadas CCAA que decidieron afrontar hace años una problemática que el legislador estatal prefirió ignorar. Ciñéndonos a las normas autonómicas con rango de ley, cabe citar la Ley de Castilla y León 11/2003, de 8 de abril, de Prevención Ambiental; la Ley de Valencia $7 / 2002$, de 3 de diciembre, de protección contra la contaminación acústica; la Ley de Cataluña 16/2002, de 28 de junio, de protección contra la contaminación acústica; la Ley de Madrid 5/2002, de 27 de junio, sobre Drogodependencia y otros trastornos auditivos (aun cuando la lucha contra el ruido solamente está prevista en puntos aislados) ${ }^{83}$; la Ley del País Vasco 3/1998, de 27 de febrero, de protección del medio ambiente; la Ley

83 Según advierte Marín Castán, resulta sorprendente que en una de las ciudades más ruidosas del mundo, la específica protección contra este tipo de agresiones se confíe a una norma sin rango de ley como el Decreto 78/1999, de 27 de mayo por el que se aprueba el régimen de protección contra la contaminación acústica. Para un análisis exhaustivo sobre las disposiciones autonómicas, estatales y comunitarias que han venido a engrosar la normativa vigente contra el ruido, ver Marín Castán, F.: "Problemas generales y aspectos constitucionales de la tutela judicial frente al ruido", en La tutela judicial frente al ruEsonela Judicial del Consejo General del Poder Judicial, Cuadernos de Derecho Judicial, Madrid, 2002, págs. 125 y ss. 
de Galicia 7/1997, de 11 de agosto, de protección contra la contaminación acústica y la Ley de Andalucía 7/1994, de 18 de mayo, de protección medio ambiental, desarrollada en materia de ruidos por el Decreto 74/1996, de 20 de febrero, por el que se aprueba el Reglamento de calidad del aire.

Ante este nuevo y esperanzador panorama normativo, respaldado por la proliferación de Sentencias del Tribunal Constitucional y del TEDH que casi siempre despiertan la atención de la doctrina, es de esperar que nuestra Administración Pública — que contará a partir de ahora con medios mucho más efectivos para hacer frente a estas agresiones- preste mucha mayor atención a este grave problema medioambiental. De esta forma se podrá evitar algo que se ha querido denunciar en estas páginas: la pasividad de la mayoría de las autoridades competentes.

\section{RECAPITULACIÓN Y CONCLUSIONES}

En relación con las numerosas demandas promovidas por particulares con la pretensión de que cesen las distintas actividades sonoras, hay que resaltar la jurisprudencia del Tribunal Europeo de Derechos Humanos de Estrasburgo que, en muchas ocasiones, ha servido de pauta a la igualmente válida y sugerente jurisprudencia constitucional.

Ambas, en efecto, han desarrollado en los últimos años, como una concreción del derecho constitucional al medio ambiente, la ecologización de determinados derechos fundamentales, el descubrimiento de una nueva dimensión ambiental en algunos derechos fundamentales por medio de la interpretación según la cual, en casos de sobresaliente gravedad, ciertos daños ecológicos pueden poner en peligro la salud o la integridad de la persona, atentando contra el derecho a la vida y la integridad física y moral (caso de nuestro Tribunal Constitucional, art. $15 \mathrm{CE}$ ), o bien lesionar el derecho de las personas a la intimidad personal y familiar y a la inviolabilidad del domicilio (caso del Tribunal Constitucional y del TEDH, arts. $18 \mathrm{CE}$ y $8 \mathrm{CEDH}$ respectivamente).

En el presente trabajo se ha pasado revista al Derecho comparado e interno relativo a la cuestión de los derechos fundamentales "no escritos» y su posible fundamento jurídico-constitucional. A diferencia de lo que ocurre en otros textos constitucionales, no hay que olvidar que nuestra Constitución no incluye una cláusula abierta de derechos. Ciertamente, el considerarlos reconocidos con base en los arts. 1.1, 10.1 o 9.2 CE supondría la aplicación de los mismos por el Tribunal Constitucional frente al legislador y acaso el reconocimiento por la jurisdicción ordinaria frente a la Administración pública. Según se explicó en su momento, podrían pasar a ser elementos objetivos del ordenamiento jurídico, pero serían derechos 
fundamentales "débiles» pues no estarían protegidos por recurso de amparo ante la jurisdicción ordinaria y el Tribunal Constitucional. Para que un "derecho nuevo" lo sea en su plenitud, en nuestro sistema, ha de considerarse implícito en alguno de los derechos reconocidos entre los arts 14 y $30 \mathrm{CE}$.

Pues bien, en la Constitución española cabe hablar de algunos derechos no enumerados de forma expresa en el texto constitucional. Es el caso del derecho de rectificación, del princípio non bis in iayede la libertad informática.

Además, la jurisprudencia del TEDH primero y del Tribunal Constitucional después han puesto de manifiesto que, aun cuando el ruido es un sector integrante del medio ambiente, en determinadas ocasiones constituye una vulneración del derecho fundamental a la intimidad personal y familiar, en el ámbito domiciliario, a lo que el Tribunal Constitucional ha añadido que el ruido puede afectar al derecho a la integridad física y moral (art. $15 \mathrm{CE}$ ). Ahora bien, es preciso recordar que dicha vulneración se condiciona rigurosamente, dificultando las posibilidades reales para que los Tribunales de Justicia puedan Ilegar a apreciarla.

Sin dejar de hacer referencia a las resoluciones más importantes dictadas por el TEDH, así como su relación con la actual doctrina de nuestro Alto Tribunal, en el presente trabajo se han estudiado especialmente las dos recientes SSTC 16/2004, de 23 de febrero, y 25/2004, de 26 de febrero. Siguiendo la pauta de la mayoría de los fallos emitidos sobre la materia objeto de estudio, ambas sentencias no han estado exentas de profundas y nada pacíficas deliberaciones a la vista de los votos particulares que en ellas se integran.

En este sentido, se ha hecho especial referencia a la STC $16 / 2004$, por haber reafirmado de manera clara y contundente los derechos fundamentales implicados en este tipo de agresiones tras una larga y dispersa evolución jurisprudencial. Antes de exponer sus líneas básicas de argumentación, se han mencionado las grandes aportaciones de la doctrina constitucional (STC 199/1996, 119/2001) y del TEDH (López Ostra, Guerra, Powel y Rayner, Hatton y otros, Moreno Gómez c. España) que han sido decisivas para el giro de la doctrina del Tribunal Constitucional.

Se ha analizado la sorprendente divergencia mantenida por las Salas Primera y Segunda de nuestro Alto Tribunal ante una posible vulneración del principio de legalidad cuyo ejercicio real y efectivo está expresamente previsto en la Constitución. En cuanto a qué doctrina pueda prevalecer en el futuro, tan solo cabe hacer especulaciones que tengan en cuenta el sentido del voto de los Magistrados en resoluciones pasadas, si bien debe subrayarse que son infinitos los matices por los que el parecer 
de cada miembro de un órgano jurisdiccional colegiado puede evolucionar. En todo caso, según lo dicho, merece la pena tener presente que la composición del Tribunal Constitucional cambió por RD de 8 de junio de 2004. En la actualidad, en el Pleno hay cuatro Magistrados que en su día aprobaron la STC 25/2004, más dos Magistrados que firmaron el voto particular a la STC 16/2004, cuatro Magistrados que no se han pronunciado sobre la cuestión, y sólo dos que se pronunciaron a favor de la STC 16/2004.

Por último, se ha comentado la muy eficaz función impulsora del Tribunal Constitucional y del TEDH por regular una materia cuya regulación manifiestamente incompleta ha contribuido a deteriorar de forma alarmante la protección solicitada por todos los que han sufrido las consecuencias de este tipo de agresiones. En este sentido, se ha aludido someramente a algunos de los logros obtenidos tanto en la normativa comunitaria como en la nacional.

Probablemente, si el ruido hubiese sido objeto de mayor atención en la anterior normativa protectora del medio ambiente, se hubiesen evitado fallos tan dispares y controvertidos como los que han sido objeto de estudio. Sin dejar de alabar la función impulsora del Tribunal Constitucional al sugerir importantes mejoras en la legislación, el problema surgido ante un fenómeno social tan grave, quizás debería haber sido resuelto por el legislador de forma mucho más temprana y exhaustiva. De hecho, según se ha puesto de relieve, la reciente Ley del Ruido 37/2003, de 17 de noviembre, ha aportado el criterio óptimo de actuación al diseñar una nueva y completa regulación sobre la contaminación acústica hasta entonces inexistente ${ }^{84}$.

Por otro lado, es preciso insistir que la controvertida respuesta dada por el Tribunal Constitucional en las dos sentencias comentadas ante supuestos tan similares, probablemente haya contribuido a aumentar la

${ }^{84}$ En términos más contundentes, se pronunciaba Martín-Retortillo en relación con la respuesta dada por nuestro legislador hasta la entrada en vigor de la reciente Ley del Ruido: "no sólo es muy tardía, habiendo transcurrido en vano un tiempo precioso en que la situación se pudrió y deterioró de forma alarmante, sino que es manifiestamente incompleta y deja muchos huecos y vacíos. Los operadores jurídicos, aún en el supuesto de que decidan actuar, hallan no pocas lagunas, que dificultan la reacción, y no hacen sino beneficiar a los desaprensivos. De hecho, el panorama que se ofrece, aún con todas las respuestas habidas, es de manifiesta inseguridad jurídica. Pensando en el ruido, en general - y no sólo en el ruido del ocio-, y en su repercusión sobre la sociedad española, se constata que no ha habido una respuesta frontal y de conjunto». Vid. 
inseguridad jurídica. Cabe preguntarse la razón de la falta de uso del procedimiento previsto en el artículo 13 de la Ley Orgánica del Tribunal Constitucional para casos como el presente, de divergencia de doctrina de una Sala frente a otra. Hay que lamentar que no se sometiera la cuestión al Pleno del Tribunal con las garantías de estabilidad y continuidad de la doctrina previstas en su propia Ley Orgánica.

En este sentido, quizás sea conveniente recordar la declaración de vinculación de la doctrina del Tribunal Constitucional prevista en el artículo 5 de Ley Orgánica del Poder Judicial: los Jueces y Tribunales deben interpretar y aplicar las leyes y reglamentos según los preceptos y principios constitucionales, conforme a la interpretación que de ellos haya hecho el Tribunal Constitucional. Como bien apunta Fernández López, esta vinculación especialmente intensa no puede considerarse excesiva o errada si se tiene en cuenta el papel dominante que, en materia de garantías constitucionales, se le reserva y en la necesidad o conveniencia de un mantenimiento doctrinal homogéneo en un ámbito de especial trascendencia para los ciudadanos como es el Título I de la Constitución. Desgraciadamente, los mecanismos previstos para garantizar esa necesaria homogeneidad en la doctrina constitucional no se han cumplido ${ }^{85}$.

\section{BIBLIOGRAFÍA}

Alonso GarcíA, C.: "La contaminación acústica», en Lecciones de Derecho Medio Ambiental $3^{a}$ edición, L. Ortega Alvarez (dir.), Lex Nova, 2002, págs. 339-357.

ARAgón ReYes, M.: "La función legislativa de los parlamentos y sus problemas actuales", en El parlamento y sus transformaciones actuales: Jornadas organizadas por la Asamblea Regional de MurciA. Garronera Morales (ed.), Tecnos, Madrid, 1990.

Betancor Rodríguez, A.: Instituciones de Derecho ambierMadrid, La

85 Por el contrario, el Tribunal Constitucional ha optado por una serie técnicas indirectas con parecido objetivo de asegurar la continuidad doctrinal que algunos entienden que no se ajustan al marco legal y al significado profundo del precedente. Para una descripción de estas técnicas, ver el comentario de Fernández López al art. 13 LOTC, incluido en la obra colectiva Comentarios a la LOTcoord. J.L Requejo Pagés, Ed. BOE 
Ley, 2001.

CACHO SÁnCHEZ, Y.: "Los ruidos, los derechos humanos medioambientales y el derecho al respeto a la vida privada y familiar: asunto Hatton y otros c. el Reino Unido", en Revista General de Derecho Euraúm 2, octubre 2003.

Cobo Del Rosal, M.: "Sobre el insoportable "delito del ruido", en La Raz n, 18 de mayo de 2004p.60.

De Otтo, I.: Derecho Constitucional. Sistema de f(AnieléBarcelona, 1987.

Díaz Revorio, F. J.: "Tribunal Constitucional y Derechos Constitucionales "no escritos", en La Justicia Constitucional en el Estado democr tico, Tirant lo Blanch, Valencia, 2000.

ENTRENA RUIZ, D.: «El ruido, ¿un problema de seguridad pública? La tipificación de infracciones y sanciones mediante ordenanzas locales: abundando en la doctrina constitucional", en Revista Interdisciplinar de Gesti n Ambientā̄úm. 67, julio 2004.

García De Enterría, E.: "La incidencia de la Constitución sobre la potestad sancionadora de la Administración: dos importantes sentencias del Tribunal Constitucional», en REDA núm. 29 (1981).

GARCía SAN JosÉ, D.: «Ruido nocturno e insomnio: los derechos a la vida privada y familiar y al respeto del domicilio frente al interés general de los vuelos de aviones durante la noche. Comentario a la Sentencia del Tribunal Europeo de Derechos Humanos de 2 de octubre de 2001, en el caso Hatton y otrocontra Reino Unido, en Revista Espa ola de Derecho Constitucional 64, enero-abril 2002.

Garrorena Morales, A.: el lugar de la ley en la Constituci n espa ola, Centro de Estudios Constitucionales, Madrid, 1980.

GonzÁlez PASTOR, C.: «La nueva Ley del Ruido: regulación administrativa y regulación penal como delito contra el medio ambiente. Comentario a la Sentencia del Tribunal Constitucional de 23 de febrero de 2004», en La Leynúm. 5982, 24 de marzo de 2004.

JimÉnEz DE PARGA, M.: "Veintitrés años de jurisprudencia del Tribunal Constitucional sobre derechos fundamentales", en Revista de Derecho POI tico de la UNE255-59, 2003-2004.

LOPERENA ROTA, D.: «El medio ambiente en el Tribunal Europeo de Derechos 
Humanos", en Repertorio Aranzadi del Tribunal Constitmúmonal, 10/2003.

López PINA, A.: "Tareas del Estado y lugar de la Ley», en Jornadas de Derecho Constitucional Comparado. Democracia representativa y parlamentarismo: Alemania, Espa a, Gran Breta a eAItópéz, Pina (dir.), Secretaría General del Senado, Servicio de Publicaciones, Madrid, 1994.

LozAno CutANDA, B.: Derecho ambiental administra,t3aved., Dykinson, Madrid, 2003.

Marín CAStÁn, F.: «Problemas generales y aspectos constitucionales de la tutela judicial frente al ruido", en La tutela judicial frente al ruido, Escuela Judicial del Consejo General del Poder Judicial, Cuadernos de Derecho Judicial, Madrid, 2002, págs. 93 y ss.

Martín-Retortillo Baquer, L.: "El ruido de los grandes aeropuertos en la jurisprudencia del Tribunal Europeo de Derechos Humanos", en Revista Vasca de Administraci n $P$ nơlulosseptiembre-diciembre 1994.

"El ruido: una pesadilla del Justicia», en Tercer encuentro de estudios sobre El Justicia de ArZaragoza, mayo 2002.

PÉREz MARTOS, J.: "La protección jurisdiccional frente al ruido (comentario a la Sentencia del Tribunal Constitucional 119/2001, de 24 de mayo), en Revista de Estudios de la Administraci númoz88 (Enero-Abril 2002).

Revenga SÁnchez, M.: "Sobre (viejos) modelos de justicia constitucional y creación de (nuevos) derechos", en Revista de Derecho Constitucional no 64, enero-abril 2002.

Rubio Llorente, F.: "El principio de legalidad», en Revista Espa ola de Derecho Constitucionaúm. 37-39 (1993), págs. 24 y ss.

RuIz Rıco, G.: El derecho constitucional al medio ambiente (dimensi $n$ jurisdicCiond/alencia, Tirant lo Blanch, 2000.

Torres Del Moral, A.: Principios de Derecho Constitucional Espa ol, (dos tomos) ,5 $5^{\text {a }}$ edición, Servicio de Publicaciones Facultad de Derecho de la Universidad Complutense, Madrid, 2004.

Estado de Derecho y democracia de partzajedición, Servicio de Publicaciones de la Facultad de Derecho de la Universidad 